\title{
Differences in effective ploidy as drivers of genome-wide endosperm expression asymmetries and seed failure in wild tomato hybrids
}

Morgane Roth ${ }^{*, 1}$, Ana M. Florez-Rueda ${ }^{*}, 2$ and Thomas Städler ${ }^{*}$

* Plant Ecological Genetics, Institute of Integrative Biology \& Zurich-Basel Plant Science Center, ETH Zurich, 8092 Zurich, Switzerland

${ }^{1}$ Current address: Agroscope, Research Division Plant Breeding, 8820 Wädenswil, Switzerland

${ }^{2}$ Current address: Plant Developmental Genetics, Department of Plant and Microbial Biology \& Zurich-Basel Plant Science Center, University of Zurich, 8008 Zurich, Switzerland 
bioRxiv preprint doi: https://doi.org/10.1101/459925; this version posted November 2, 2018 . The copyright holder for this preprint (which

was not certified by peer review) is the author/funder, who has granted bioRxiv a license to display the preprint in perpetuity. It is made available under aCC-BY-NC-ND 4.0 International license.

Running title: expression asymmetries in hybrid endosperm

Keywords: endosperm, hybrid seed failure, effective ploidy, gene expression, wild tomatoes

Corresponding author: Dr. Thomas Städler, Plant Ecological Genetics, Institute of Integrative Biology \& Zurich-Basel Plant Science Center, ETH Zurich, Universitätstrasse 16, 8092 Zurich, Switzerland. Phone: +41-44-6327429; E-mail: thomas.staedler@env.ethz.ch 


\section{Abstract}

2 Endosperm misdevelopment leading to hybrid seed failure is a common cause of postzygotic

3 isolation in angiosperms and is observed in both interploidy and homoploid crosses between

4 closely related lineages. Moreover, parental dosage is critical for successful endosperm and seed

5 development, typically requiring a ratio of two maternal to one paternal genome(s) in within-

6 species crosses. The recently revived concept of 'effective ploidy' can largely explain the

7 outcome of experimental crosses that (partly) ameliorate hybrid seed failure by manipulating the

8 actual ploidy in one of the parents. However, genome-wide expression perturbations

9 concomitant with levels of hybrid seed failure have yet to be reported. The tomato clade

10 (Solanum section Lycopersicon), encompassing closely related diploids with partial-to-complete

11 hybrid seed failure and diverse mating systems, provides outstanding opportunities to study these

12 issues. Here we compared replicated endosperm transcriptomes from six crosses within and

13 among three wild tomato lineages. Strikingly, both strongly inviable hybrid crosses displayed

14 conspicuous, asymmetric expression perturbations with strong signatures of cross direction. In

15 particular, Solanum peruvianum, the species inferred to have evolved higher effective ploidy

16 than the other two, drove hybrid expression landscapes in both maternal and paternal roles. This

17 global expression divergence was mirrored in functionally important gene families such as

18 transcription factors and E3 ubiquitin ligases, and revealed differences in cell-cycle tuning

19 between lineages that match phenotypic differences in developing endosperm and mature seed

20 size between reciprocal crosses. Our work initiates the exploration of links between parental

21 conflict, genomic imprinting, expression dosage and hybrid seed failure in flowering plants. 


\section{Introduction}

23 Hybrid seed failure (HSF) is a common phenotype mediating early-acting postzygotic reproductive isolation in flowering plants. HSF does not necessarily result from F1 embryo defects as embryos may be rescued from developing seeds and grown to become fertile plants (Sharma et al. 1996). Such observations have been widely interpreted as evidence for hybrid endosperms' compromised ability to correctly nourish the embryo (Lester and Kang 1998; Sekine et al. 2013; Rebernig et al. 2015). As the products of double fertilization, embryo and endosperm are genetically closely related, yet these fertilization products are strongly dissimilar, concomitant with their different genome composition (embryo diploid, 1m:1p; endosperm triploid, 2m:1p) and methylation profiles (Gehring et al. 2009). This original 'brotherhood' between endosperm and embryo evolved over long periods of coevolutionary history, which might have contributed to the success of flowering plants (Baroux et al. 2002).

The frequent occurrence of HSF in interploidy crosses has been interpreted to be a consequence of endosperm sensitivity to parental dosage, establishing a reproductive barrier termed the 'triploid block' (Köhler et al. 2010; Stoute et al. 2012). A well-known feature of interploid seed failure are the typically contrasting phenotypes of reciprocal developing and/or mature hybrid seeds (Cooper and Brink 1945; Valentine and Woodell 1963; Scott et al. 1998; Leblanc et al. 2002). Specifically, these asymmetric phenotypes comprise smaller seeds when the ovule parent is of higher ploidy ('maternal-excess phenotype') and larger seeds when the pollen parent is of higher ploidy ('paternal-excess phenotype'; Haig and Westoby 1991). As endosperm size — which largely determines mature seed size — is affected in corresponding directions in such reciprocal interploidy crosses, parental-excess phenotypes have been regarded as a direct consequence of asymmetric parental dosage in their endosperms (Scott et al. 1998; Sabelli and Larkins 2009; Stoute et al. 2012).

Importantly, such inferred dosage sensitivity is also suspected to play a role in the developmental trajectory and (often) abortion of homoploid hybrid seeds with similar symptoms of parental excess (Josefsson et al. 2006; Rebernig et al. 2015; Oneal et al. 2016; Lafon-Placette et al. 2017, 2018). Phenotypic asymmetries between seeds from reciprocal homoploid crosses

50 indicate that incompatibilities expressed in hybrid endosperm encompass parental effects. These phenomena might be caused by differences in so-called 'effective ploidy, a compound property thought to determine dosage requirements for specific genes in a given lineage (reviewed in 
53 Lafon-Placette and Köhler 2016), and in classical work on tuber-bearing Solanum species

54 proposed as 'endosperm balance number' (EBN; Johnston et al. 1980; Ortiz and Ehlenfeld 1992). In crosses between homoploid species with different effective ploidy, the species with higher effective ploidy would mimic the lineage with higher actual (karyotypic) ploidy in an interploidy cross.

From an evolutionary point of view, variation in effective ploidy or 'genetic strength' is regarded as a potential consequence of divergence between species in levels of parental conflict. According to this line of thinking, maternal interests ought to restrict seed growth to allocate resources equally among all seeds (from potentially different fathers). In contrast, paternal interests ought to promote growth only for their own sires in the face of other potential fathers, setting up competition for resource allocation between seeds from the same mother (Haig and Westoby 1991; Brandvain and Haig 2005). Under this scenario, the smaller seeds observed in maternal-excess crosses could be a manifestation of growth restrictions of maternal origin, while the larger seeds in paternal-excess crosses might reveal weakened maternal control over resource allocation, thus leading to paternally-driven overgrowth.

Thus far, dissimilar seed phenotypes have been revealed in interploidy crosses, yet without addressing variability in parental conflict strength between lineages. Indeed, while interploidy crosses can reveal parental effects, parental conflict is not expected to depend on ploidy level per se. Arguably, studies on homoploid interspecific hybrids are more suitable to investigate whether parental conflict strength has evolved in response to differences in mating system, long-term demographic history, and/or other evolutionary forces. Relevant studies have recently been performed in two Brassicaceae genera, Arabidopsis and Capsella, where it was shown that the parent with the outcrossing breeding system (A. lyrata, A. arenosa and C. grandiflora, respectively) drives seed phenotypes of maternal- and paternal-excess (Josefsson et al. 2006; Rebernig et al. 2015; Lafon-Placette et al. 2017, 2018); experimentally increasing the ploidy of the inbreeding species partly restored seed viability (Josefsson et al. 2006; Lafon-Placette et al. 2017). Beyond these phenotypic evidences, divergence in dosage between parental species of flowering plants and its consequences for genome-wide expression modulation appear to not have previously been quantified.

To date, genome-wide studies on endosperm gene expression have mainly focused on 83 characterizing genomic imprinting, i.e. the parent-of-origin-dependent expression of genes. A 84 trend for elevated expression of imprinted genes in species with higher parental conflict was 
found between closely related species, but it is currently not known whether this might contribute to incidences of HSF (Klosinska et al. 2016; Roth et al. 2018b). Of note, genomic imprinting is extensively perturbed in failing wild tomato hybrid endosperm (Florez-Rueda et al. 2016), but it is unclear whether mis-imprinting per se or total expression-level changes of functionally important genes (plausibly including imprinted genes) underpin hybrid seed abortion. We may hypothesize that parental imbalances caused by divergent effective ploidies in homoploid crosses affect global expression levels and dosage-sensitive processes such as genomic imprinting. Moreover, we expect such parental imbalances to be reflected by opposite patterns of expression change in the reciprocal crosses.

Wild tomatoes (Solanum section Lycopersicon) provide a well-suited plant system to study developmental and evolutionary questions on HSF (Florez-Rueda et al. 2016; Roth et al. 2018a). We have recently shown that crosses between $S$. arcanum var. marañón (A), S. chilense (C) and S. peruvianum $(\mathrm{P})$ result in different degrees of endosperm disruption leading to partial or complete seed inviability (Roth et al. 2018a). In particular, crosses between A and C yield variable proportions of viable and inviable seeds (here categorized as 'weak-HSF') whereas crosses between $\mathrm{P}$ and either A or C result in near-complete seed failure (termed 'strong-HSF';

101 Figure S1). Moreover, marked phenotypic asymmetries are characteristic of seeds from

102 reciprocal crosses of the strong-HSF category, where endosperms fathered by species $\mathrm{P}$ (i.e.

103 from crosses AP and CP) correspond to paternal-excess phenotypes and endosperms of $\mathrm{P}$ maternal plants (i.e. from crosses PA and PC) correspond to maternal-excess phenotypes (Florez-Rueda 2014; Roth et al. 2018a). We thus hypothesized that lineage P experienced higher levels of parental conflict that led to its increased effective ploidy compared to $\mathrm{C}$ and $\mathrm{A}$ during their evolutionary divergence.

The present study seeks to (i) quantify molecular perturbations of gene expression levels in 109 (partly or entirely) failing wild tomato endosperm, (ii) assess the prediction of genome-wide 110 asymmetries in patterns of endosperm expression levels between reciprocal strong-HSF crosses,

111 (iii) identify candidate genes/gene families with potentially important roles in expression 112 perturbation, and (iv) discuss the role of parental conflict-driven differences in effective ploidy 113 in causing or contributing to hybrid seed failure. 


\section{Materials and Methods}

\section{$115 \quad$ Plant material and crosses}

116 Seeds were obtained from the Tomato Genetics Resource Center (TGRC, University of

117 California, Davis, USA; https://tgrc.ucdavis.edu). We crossed three genotypes (one per species)

118 in a full diallele design with all reciprocal crosses producing seed phenotypes typical for weak or 119 strong seed inviability, respectively (Roth et al. 2018a; Figure S1). Genotypes were chosen from 120 population LA2185 (Amazonas, Peru) for S. arcanum var. marañón (A), population LA4329

121 (Antofagasta, Chile) for S. chilense (C) and population LA2744 (Arica and Parinacota, Chile) for 122 S. peruvianum (P) to be used in hybrid crosses (Figure S2). In addition, we chose three

123 genotypes from additional populations of each species in order to perform intraspecific

124 reciprocal crosses (referred to as 'controls'; Figure S2). The corresponding populations are

125 LA1626 (Ancash, Peru) for A, LA2748 (Tarapaca, Chile) for C and LA2964 (Tacna, Peru) for P.

126 The latter three populations were not used in hybrid crosses. As detailed in Roth et al. (2018a),

127 all crosses produced normal quantities of seeds per fruit. Plants were grown from seed in an 128 insect-free greenhouse at ETHZ (Lindau-Eschikon, canton Zurich, Switzerland). They were 129 regularly repotted in 5-1 pots using fresh soil (Ricoter Substrate 214, Ricoter Erdaufbereitung 130 AG, Aarberg, Switzerland) and fertilizing granules (Gartensegen, Hauert HBG Dünger AG,

131 Grossaffoltern, Switzerland). Additional liquid fertilizer was applied once or twice per 132 month depending on the season (Wuxal ${ }^{\circledR}$ NPK solution, Aglukon Spezialdünger GmbH and Co.

133 KG, Düsseldorf, Germany). Plants were watered two to four times per week.

134 Well before the onset of the experiments, cuttings yielded multiple ramets per genotype,

135 from which we chose three to serve as biological replicates. All clones were maintained in a 136 climate chamber for the duration of the whole experiment (12 h light at 18 Klux and 50\%

137 relative humidity, $12 \mathrm{~h}$ darkness at 0 Klux with $60 \%$ relative humidity). Reciprocal crosses were 138 named with the two initial letters of parental lineages within brackets (all reciprocal crosses are:

$139[\mathrm{AC}],[\mathrm{AP}],[\mathrm{CP}],[\mathrm{AA}],[\mathrm{CC}],[\mathrm{PP}])$, and individual crosses designated by the initial letters of 140 parental lineages without brackets, indicating the cross direction 'mother $\times$ father': AA1,

141 LA2185A $\times$ LA1626B; AA2, LA1626B $\times$ LA2185A; CC1, LA4329B $\times$ LA2748B; CC2,

142 LA2748B $\times$ LA4329B; PP1, LA2744B $\times$ LA2964A; PP2, LA2964A $\times$ LA2744B; AC, 143 LA2185A $\times$ LA4329B; CA, LA4329B $\times$ LA2185A; AP, LA2185A $\times$ LA2744B; PA, LA2744B $144 \times$ LA2185A; CP, LA4329B $\times$ LA2744B; PC, LA2744B x LA4329B. This implies that AC, AP, 
and $\mathrm{AA} 1$ share the same mother, that $\mathrm{CA}, \mathrm{CP}$, and $\mathrm{CC} 1$ share the same mother, and that $\mathrm{PA}, \mathrm{PC}$, and PP1 share the same mother. Each cross was performed three times using clonal replicates of each genotype. Fruits were sampled 12 days after manual pollinations (12 DAP)—corresponding to the early globular embryo stage-embedded, and endosperms were sampled from fruit cryosections via laser-assisted microdissection. Methods for endosperm sampling, RNA extraction, library preparation and sequencing are detailed in our previous study (Roth et al. 2018b).

\section{Alignment and counting methods}

154 Short read alignment was done as previously described (Roth et al. 2018b). Briefly, RNA-Seq 155 quality assessment of all samples was performed with the FastQC program

156 (http://bioinformatics.babraham.ac.uk/projects/fastqc/). Adapters were removed with cutadapt 157 (Martin 2011). Trimming and quality filtering were done with the Perl script trimmingreads.pl 158 from the NGSQC Toolkit version 2.3 (Patel and Jain 2012). Read mapping was performed with 159 TopHat version 2.1.0 (Trapnell et al. 2009) against the SL2.50 reference genome of the 160 cultivated tomato var. Heinz (The Tomato Genome Consortium 2012) with the corresponding 161 annotation ITAG2.4 (International Tomato Annotation Consortium; https://solgenomics.net/). 162 Mapping quality check was done with Qualimap version 2.2 (Okonechnikov et al. 2016) and 163 RSeQC (Wang et al. 2012). Total reads per gene were counted from bam files with HTseq 164 (Anders et al. 2015) using the gff ITAG2.4 annotation file (The Tomato Genome Consortium 165 2012). Only reads with mapping quality above 20 were retained.

166

\section{Statistical analyses}

168 Differential gene expression analysis (DGE) was performed with the R package EdgeR 169 (Robinson et al. 2010; R Development Core Team 2014). Only genes with at least one read 170 count per million in at least two of the 36 libraries were kept, resulting in a set of 22,006 genes.

171 We used Multidimensional Scaling (MDS) plots to assess variation between biological 172 replicates, using the function plotMDS in EdgeR and target groups 'species' for intraspecific 173 crosses and 'cross type' for the whole dataset. A negative binomial model was fitted to each 174 gene using individual crosses as factors, estimating trended dispersions (variance parameters). 175 Differentially Expressed Genes (DEGs) were identified in the selected pairwise comparisons 
176 using different contrasts with a generalized linear model likelihood ratio test $(P$-value correction

177 with the Benjamini-Hochberg method for a false discovery rate [FDR] of 5\%).

178 In each comparison, we used specific contrasts to compare two classes of crosses according

179 to different criteria: (i) their seed phenotype (e.g. in the 'strong-intra' comparison, strongly

180 abortive crosses were compared to intraspecific crosses by pooling all replicates of all strong-

181 HSF crosses together (i.e. AP, PA, CP, and PC) and comparing them to all replicates of all

182 intraspecific crosses pooled together (i.e. AA1, AA2, CC1, CC2, PP1, and PP2)); (ii) hybrids

183 compared to their respective intraspecific cross sharing the same mother (e.g. in the 'PA-PP1'

184 comparison, all replicates of the PA cross were compared to all replicates of the PP1 cross); (iii)

185 cross direction by comparing reciprocal crosses (e.g. in the 'PA-AP' comparison, all replicates of

186 the PA cross were compared to all replicates of the AP cross); and (iv) the species in

187 intraspecific crosses (e.g. in the '[AA]-[CC]' comparison, we compared all replicates of AA1

188 and $\mathrm{AA} 2$ to all replicates of $\mathrm{CC} 1$ and $\mathrm{CC} 2$ ); in total we report 18 different contrasts (Table S1,

189 sheet 'Contrasts'). Count data used for creating heat maps were obtained from normalized counts

190 per million, averaged across replicates for each cross. Heat maps were plotted with the R

191 package 'gplots' using hierarchical clustering (R Development Core Team 2014; Warnes et al.

192 2016). The R package ‘topGO’ (Alexa and Rahnenführer 2016) was used to identify enriched

193 Gene Ontology (GO) terms from ITAG 2.4 downloaded from Plant Ensembl Biomart

194 datamining platform (Kinsella et al. 2011), using as gene universe the set of 22,006 endosperm-

195 expressed genes. Venn diagrams were obtained with the R package 'venneuler' (Wilkinson

196 2011).

\section{Data availability}

199 Raw sequence data for the RNA-sequencing dataset used in this study are available from the

200 Sequence Read Archive (https://race.ncbi.nlm.nih.gov/Traces/sra/) with the accession numbers

201 PRJNA427095 (18 hybrid endosperm libraries), SRP132466 (18 within-species endosperm

202 libraries and five parental plants; Roth et al. 2018b), and SRX1850236 (parent LA4329B;

203 Florez-Rueda et al. 2016). Supplemental Material, Figure S1 details the distribution of seed

204 viability in all crosses used in this study, which are a subset of a larger phenotypic study of

205 (hybrid) seed viability (Roth et al. 2018a). Figure S2 is a diagram of the crossing design

206 representing the six reciprocal crosses used for our endosperm RNA-Seq experiment. Table S1 is

207 as large Excel table containing four data sheets: 'Contrasts' contains the list of 18 comparisons 
with their corresponding contrasts used in this study, 'DEGs' summarizes differential gene expression (DGE) for each of them, 'GO_enrichment' summarizes GO-term enrichments for differentially expressed genes (DEGs) in selected categories, and 'DGE_imprinted_genes' lists the status of candidate imprinted genes and their differential expression in all tested contrasts.

\section{Results and Discussion}

\section{Molecular responses to hybridization correspond to hybrid seed failure severity}

215 Seeds with similar phenotypes are likely to have similar expression patterns in the endosperm 216 and low proportions of DEGs between them. In turn, we hypothesized that the magnitude of 217 gene expression differences between two crosses would broadly match their developmental 218 trajectories (along the gradient intraspecific - weak HSF - strong HSF). We assessed this 219 hypothesis with a suite of DGE analyses. After filtering our dataset for lowly expressed genes across the 36 libraries, 22,006 genes remained for DGE analysis, indicating that $63.4 \%$ of the

221 ITAG2.4-annotated genes were jointly expressed in the 12-DAP endosperm of our various cross

222 types. The multidimensional scaling (MDS) plot using expression data from only the

223 intraspecific crosses revealed that samples broadly group by species and cross direction (Figure

224 1A). In particular, differences in the overall gene expression landscape between [CC] and [PP]

225 endosperms appear to be fewer than between [CC] and [AA] or [PP] and [AA] endosperms: 817

226 DEGs were found between [PP] and [CC], 1,226 DEGs between [CC] and [AA], and 1,184

227 DEGs between [PP] and [AA]. This apparent genome-wide expression divergence broadly

228 reflects the differences in divergence time between A, C and P (Städler et al. 2008; Beddows et 229 al. 2017). A positive correlation between genomic and expression divergence is expected from 230 theory (Nuzhdin et al. 2004; Renaut et al. 2012). However, while our results support this notion, 231 the correlation between expression and sequence divergence appears to be either positive 232 (Nuzhdin et al. 2004; Khaitovich et al. 2005; Renaut et al. 2012) or non-significant (Jeukens et 233 al. 2010; Wolf et al. 2010; Moyers and Rieseberg 2013) in previous empirical studies.

234 The global expression landscape represented by the joint analysis of all 36 samples 235 revealed several expression profiles corresponding to different seed phenotypes (Figure 1B); the $236 \mathrm{y}$-axis mainly separates intraspecific and weak-HSF crosses $[\mathrm{AA}],[\mathrm{CC}],[\mathrm{PP}]$ and $[\mathrm{AC}]$ from 237 strong-HSF crosses [AP] and [CP]. We quantified these expression changes and found that many 238 more genes are differentially expressed between strong-HSF ([AP] and [CP]) and intraspecific 
endosperms ([AA], $[\mathrm{CC}]$ and $[\mathrm{PP}])$ than between weak-HSF ([AC]) and intraspecific endosperms (3,026 vs. 682 DEGs; Figure 2A; Table S1, sheet 'DEGs'). Interestingly, 85.5\% of

241 DEGs between strong-HSF and intraspecific endosperms overlap with DEGs between strong-

242 HSF and weak-HSF endosperms (with the same direction of expression changes relative to 243 strong-HSF endosperms; Table S1, sheet 'DEGs'). Expression differences in hybrid endosperms 244 are likely a product of hybridization per se (Hegarty et al. 2009; Combes et al. 2015; Raza et al. 245 2017), but expression perturbation may also be expected to be stronger when parental species are 246 more genetically diverged (Landry et al. 2007; Stelkens and Seehausen 2009; He et al. 2010).

247 Because expression differences among intraspecific crosses reflect genetic divergence between

248 lineages (Figure 1A), we might have expected [CP] to exhibit the least-altered expression pattern 249 among all hybrids. To the contrary, $[\mathrm{CP}]$ and $[\mathrm{AP}]$ hybrid endosperms revealed the most 250 dissimilar expression patterns compared to their parental intraspecific crosses, while [AC] endosperms were close to their parental intraspecific crosses in terms of overall expression

252 landscape (Figures 1B, 2B). Also, interspecific expression differences contributed more to DEGs 253 observed between individual hybrids and their corresponding intraspecific cross (sharing the 254 same mother) in weak-HSF hybrids (52.5-54.4\%) than in strong-HSF hybrids (only 19.3$25531.9 \%$ ). This suggests that gene expression divergence between parental species alone cannot 256 explain the extensive expression changes in strongly abortive endosperms (Figure 3); rather, 257 epistatic interactions might rewire gene regulation and generate unique expression landscapes in $258[\mathrm{AP}]$ and $[\mathrm{CP}]$ hybrids which might be responsible for their extreme phenotypes and nearcomplete inviability (Renaut et al. 2009; Dion-Côté et al. 2014; Roth et al. 2018a).

As a consequence of extensive transcriptomic changes, a wide range of biological functions were affected in strong-HSF endosperms. DEGs between strong-HSF and intraspecific

262 endosperms were enriched for carbohydrate and lipid metabolism, transcription regulation, 263 chromatin conformation, cell cycle, cell structure (cell wall, microtubules), signalling (peptides, 264 hormones, response to stress) and transport (100 GO terms; Table S1, sheet 'GO_enrichment'). 265 The far fewer DEGs between weak-HSF and intraspecific endosperms were mainly enriched for 266 terms related to carbohydrate and lipid metabolism (34 GO terms; Table S1, sheet

267 'GO_enrichment'). Changes related to signalling and cell wall modifications have been reported 268 as potential contributors to HSF in Arabidopsis hybrid endosperm (Burkart-Waco et al. 2013), 269 but functions relating to global transcriptome changes during endosperm-based HSF remain 270 poorly documented. Interestingly, functions enriched among imprinted genes (i.e. those with 
271 parent-of-origin-dependent expression) whose expression levels may be critical for seed

272 development, seem to overlap with perturbed functions observed in strong-HSF endosperms. In

273 particular, ten enriched GO terms found among strong-HSF DEGs were in common with GO

274 terms enriched among wild tomato imprinted genes (Roth et al. 2018b; Table S1, sheet

275 'GO_enrichment'). These GO terms correspond mainly to transcription factor activity, metabolic 276 processes and signalling and are also found enriched among imprinted genes in other species

277 such as A. thaliana, rice, maize and sorghum (Gehring et al. 2011; Luo et al. 2011; Waters et al.

278 2013; Zhang et al. 2016). Focusing on 58 conserved imprinted genes previously identified in our

279 three wild tomato species (Roth et al. 2018b), we found that 23 were differentially expressed in

280 strong-HSF endosperm vs. only four in weak-HSF endosperm, when compared to intraspecific

281 crosses (Table S1, sheet 'DGE_imprinted_genes'). While we have previously shown that

282 maternal-to-paternal expression ratios are markedly perturbed in abortive [CP] crosses (Florez-

283 Rueda et al. 2016), our results demonstrate that total expression levels of imprinted genes are

284 also affected and could contribute to HSF in strong-HSF crosses.

285

\section{Expression asymmetries between reciprocal crosses match parental-excess phenotypes}

287 For the entire transcriptome data set, we found the strongest expression differences between the

288 reciprocals of strong-HSF crosses. Indeed, the expression landscapes of crosses with P as the 289 ovule parent (PA and $\mathrm{PC}$ ) on the one hand and crosses with $\mathrm{P}$ as the pollen parent ( $\mathrm{AP}$ and $\mathrm{CP}$ )

290 on the other hand, are fundamentally dissimilar (x-axis of the MDS plot; Figure 1B). This

291 marked expression divergence corresponds to opposite seed phenotypes, comprising larger seeds

292 in AP and CP crosses ('paternal excess'-like) and smaller seeds in PA and PC crosses ('maternal 293 excess'-like; see Introduction).

294 The DGE analysis revealed that about one third of all endosperm-expressed genes were

295 differentially expressed between both the PA and AP ( $n=7,227$ genes) and the PC and CP

296 crosses $(n=7,153$ genes; Figure 2C). This indicates profound parental dosage differences

297 between reciprocals which qualitatively inherit the same parental genomes but differ in the

298 dosage from each parent due to the asymmetric $2 \mathrm{~m}: 1 \mathrm{p}$ endosperm genomic content. In both the

$299[\mathrm{AP}]$ and $[\mathrm{CP}]$ reciprocal crosses, more genes were overexpressed when $\mathrm{P}$ was in the paternal

300 than when it was in the maternal role (Figure 2C). Moreover, of these two sets of DEGs, 4,477

301 genes were in common and shared the same direction of expression change in both the 'PA-AP'

302 and 'PC-CP' comparisons (only 127 genes showed opposite gene expression changes between 
303 them). This high proportion of shared gene identity and expression change implies that the strong-HSF endosperms respond in a highly symmetric fashion relative to parent $\mathrm{P}$, indicating that the relative dosage of $\mathrm{P}$ (two as ovule parent and one as pollen parent) drove global expression changes between these two reciprocal hybrid crosses. We performed a functional enrichment analysis for the 4,320 GO-annotated DEGs shared in the two comparisons 'PA-AP' and 'PC-CP' (with the same direction of expression change with respect to the P parent; Table S1, sheet 'GO_enrichment'). Overall, these DEGs were mainly enriched for expression regulation, chromatin modifications and a large number of biosynthetic and catalytic processes

311 (Table 1; Table S1, sheet 'GO_enrichment'). Transcription was affected from initiation to RNA 312 maturation (DNA binding, RNA polymerase II, tRNA, snRNA, posttranscriptional regulation of 313 gene expression; Table 1; Table S1, sheet 'GO_enrichment'). The expression of genes relating to 314 chromatin modifications was also highly divergent between these crosses (helicases, nucleosome, replication initiation, chiasma assembly; Table 1; Table S1, sheet 'GO_enrichment').

DEGs between reciprocal crosses can reveal functions preferentially controlled by one parent that are perturbed in hybrid endosperms. For example, transcription and chromatin-related activities were more often — but not exclusively—enriched among genes overexpressed with $\mathrm{P}$ as pollen parent (Table S1, sheet 'GO_enrichment'). Other functions seemed to be more specifically overexpressed when $\mathrm{P}$ was the ovule parent, such as energy metabolism (e.g. starch and lipids), stress signals, cell-cycle control (protein phosphorylation, protein serine/threonine

323 kinase and auxin-related terms) and cell architecture (cell wall; Table 1; Table S1, sheet

324 'GO_enrichment'). Also, important functional categories among candidate imprinted genes such as DNA-binding (Waters et al. 2011; Roth et al. 2018b) were enriched among DEGs between reciprocal strong-HSF crosses (Table 1; Table S1, sheet 'GO_enrichment'). We found that a

327 large proportion of wild tomato conserved imprinted genes were differentially expressed 328 between CP and PC (39 out of 58 genes) and between AP and PA (29 out of 58 genes). In 329 particular, maternally expressed genes (MEGs) were mostly overexpressed in maternal-excess 330 endosperms (32/32 differentially expressed MEGs overexpressed in PC-CP and 20/22 MEGs 331 differentially expressed MEGs overexpressed in PA-AP) while paternally expressed genes 332 (PEGs) tended to be overexpressed in paternal-excess endosperms (7/7 differentially expressed 333 PEGs overexpressed in CP-PC and 5/7 differentially expressed PEGs overexpressed in AP-PA). 334 These expression patterns might indicate that parental excess alters specific dosage mechanisms 
regulating the expression of imprinted genes, which is potentially lethal for the endosperm and thus the developing seed (Lafon-Placette et al. 2018).

Because transcription regulation seems to be deeply affected in reciprocal strong-HSF crosses, we scrutinized expression changes of transcription factors (TFs) and found extensive expression changes among WRKY and MADS-Box TFs (Figure 4A, B). In the WRKYannotated genes, expression was homogeneous between intraspecific and weak-HSF crosses, but markedly different in strong-HSF endosperms. Two sets of genes were respectively over- and underexpressed in all strong-HSF crosses when compared to intraspecific and weak-HSF crosses. Two other sets of genes exhibited different expression levels between reciprocals of [AP] and [CP] (Figure 4A). The WRKY TF family is very diverse and involved in several major developmental processes including seed development (Rushton et al. 2010). One WRKY TF, TRANSPARENT TESTA GLABRA2, has been reported as a MEG in A. thaliana for which accession-specific dosage is essential for seed survival and involved in the control of endosperm cellularization (Dilkes et al. 2008). Among MADS-Box TFs, we also observed two subsets of over- and underexpressed genes in paternal-excess endosperms AP and CP compared to all other cross categories (Figure 4B). MADS-Box genes such as AGAMOUS-LIKE (AGL) genes are linked to the Polycomb Repressive Complex (PRC) and involved in A. thatiana endosperm cellularization during development (Kang et al. 2008; Walia et al. 2009). The paternal-excess phenotype of $A$. thaliana $\times A$. arenosa interspecific seeds has been linked to the overexpression of several AGL genes in the developing endosperm (Walia et al. 2009), while downregulation of AGL62 in A. thaliana osd1 mutants results in a maternal-excess phenotype (Kradolfer et al. 2013).

\section{Higher effective ploidy of $P$ might underlie phenotypic and transcriptomic asymmetries}

359 The phenotypic asymmetries between reciprocal, inviable hybrid crosses [AP] and [CP] coincide 360 with seed phenotypes typically observed in interploidy crosses (see Introduction). However, P does not have an increased ploidy as all three species studied here are diploid. Although P does not exhibit higher genome-wide expression levels (Roth et al. 2018b), our DGE analysis found more genes overexpressed than underexpressed in $[\mathrm{PP}]$ endosperm compared to either $[\mathrm{AA}]$ or

$364[\mathrm{CC}]$ endosperm, with an overlap of 390 genes overexpressed in [PP] in both comparisons (PP365 AA up =1,471; PP-AA down =1,176; PP-CC up = 971; PP-CC down = 851; Table 2; Table S1, 366 sheet 'DEGs'). This indicates that compared to both A and C, lineage P features increased 
expression in the endosperm that is not observed genome-wide but rather restricted to a subset of genes. Interestingly, among the common set of 390 genes overexpressed in [PP] compared to both [CC] and [AA], a sizable fraction $(n=252,64.6 \%)$ comprises genes either overexpressed in both maternal-excess crosses (PA and PC compared to AP and CP, $n=129$ ) or overexpressed in both paternal-excess crosses (AP and CP compared to PA and PC, $n=123$; Table S1, sheet 'DEGs'). From these sets of genes, genes overexpressed in maternal-excess crosses are mainly enriched for nutrient reservoir activity $(P=0.0145)$ and galactose metabolism $(P=0.0037)$, and genes overexpressed in paternal-excess crosses are enriched for DNA binding $(P=3.00 \mathrm{e}-05)$, transcription regulation $(P=8.00 \mathrm{e}-05)$ and biosynthetic process $(P=3.55 \mathrm{e}-05)$. These enrichments possibly reflect increased maternal influence on resource allocation in maternalexcess endosperms and increased paternal influence on the control of gene expression and growth, respectively.

It has recently been shown that imprinted genes in Capsella, and especially PEGs, tend to have increased expression in species with the highest effective ploidy (Lafon-Placette et al. 2018). In our recent study on wild tomatoes, only a small fraction of candidate imprinted genes were significantly differentially expressed between $[\mathrm{AA}],[\mathrm{CC}]$ and $[\mathrm{PP}]$, and these were exclusively MEGs (Roth et al. 2018b; Table S1, sheet 'DGE_imprinted_genes'). MEGs overexpressed in $[\mathrm{PP}]$ were mostly found to be overexpressed in maternal-excess crosses PA and PC (6 of 7 in PA and 4 of 5 in PC; Table S1, sheet 'DGE_imprinted_genes'). Thus, an increased expression of imprinted genes in P might contribute only marginally to expression asymmetries observed between reciprocals of the strong-HSF crosses. Alternatively, the contribution of imprinted genes might be underestimated because more imprinted genes still remain to be identified due to technical limitations (e.g. lack of parental polymorphism for many genes in the crosses used; Roth et al. 2018b).

Among the 41 putative AGL genes expressed in wild tomato endosperm, we found that 28 were jointly overexpressed in both paternal-excess crosses (30 of 34 DEGs in CP-PC and 29 of 31 DEGs in AP-PA comparisons). Among them, eight were also overexpressed in [PP] compared to both [CC] and [AA] endosperms. This pattern of expression suggests that these eight AGL genes might be paternally expressed, but their imprinting status could not be assessed due to lack of SNPs between our parental plants (only one AGL gene was polymorphic in P and not imprinted; Roth et al. 2018b). Yet, AGL genes are potentially subject to imprinting in the endosperm, as shown by the first-ever identified PEG PHERES1, and further AGL genes being 
maternally or paternally expressed in Arabidopsis (Köhler et al. 2003; Shirzadi et al. 2011; Bai and Settles 2015). Overall, our data indicate increased expression levels in species $P$ for genes known to be critical for seed size and seed viability, such as AGL genes. This might reflect the increased effective ploidy of this species as an evolutionary consequence of higher levels of parental conflict in P compared to both A and C (Lafon-Placette and Köhler 2016; LafonPlacette et al. 2018; Roth et al. 2018b).

405

Molecular functions underlying parental excess reveal differences in cell-cycle tuning

GO terms associated with genes differentially expressed between maternal- and paternal-excess crosses (i.e. PA and PC versus AP and CP, respectively) indicated contrasting cell cycle regimes. DNA replication and chiasma assembly were enriched among genes overexpressed in paternalexcess endosperms, indicating that AP and CP endosperm cells were probably still dividing at 12 DAP, while proliferation had most likely stopped in the corresponding PA and PC endosperms (Table S1, sheet 'GO_enrichment'). Our previously published morphological measurements of various [CP] seed compartments between 10 and 13 DAP bolster this inference (Roth et al. 2018a). Also, the enrichment in cell cycle control- and cell wall-related terms in DEGs between hybrid endosperms with $\mathrm{P}$ in the maternal vs. paternal role (i.e. PA and $\mathrm{PC}$ versus $\mathrm{AP}$ and $\mathrm{CP}$, respectively) is plausibly linked to cell-proliferation differences observed between these endosperms. Related to this, we found striking expression asymmetries in E3 ubiquitin ligases whose protein products are involved in the control of the cell cycle (Inzé and De Veylder 2006; Figure 4C). Among the 20 E3 ubiquitin ligase genes expressed in our data set, eight were overexpressed in maternal-excess compared to paternal-excess endosperms, while only one gene was differentially expressed between the weak-HSF cases CA and AC (Table S1, sheet 'DEGs'). phenotypes, combined with an increased response to auxin (Table S1, sheet 'GO_enrichment') which is known to exert negative control of cell division (John et al. 1993; Schruff et al. 2006; Orozco-Arroyo et al. 2015). A. thaliana arf mutants bear a non-functional AUXIN RESPONSE FACTOR 2 (ARF2) and a paternal-excess phenotype with enlarged seeds due to delayed and extended cell divisions in seed tissues (Schruff et al. 2006). This indicates that maternal factors control the response to auxin, which is responsible for the control of cell cycle transitions. Interestingly, five ARFs were found to be MEGs in wild tomato endosperm, and three of them 
431 were overexpressed in maternal-excess phenotypes (Solyc04g081240.2, Solyc07g043610.2,

432 Solyc11g069500.1; Roth et al. 2018b; Table S1, sheet 'DEGs'). Signals for cell differentiation

433 and response to hormones involved in cell differentiation and seed maturation, such as

434 brassinosteroids and abscisic acid (Orozco-Arroyo et al. 2015), were overrepresented among

435 genes overexpressed in the maternal-excess endosperms (Table S1, sheet 'GO_enrichment').

436 Compared to intraspecific PP1 endosperm, genes involved in mitotic chromosome condensation

437 and regulation of G2/M transition of the mitotic cell cycle were mainly underexpressed in PA

438 and PC (category 'down in PA-PP1 \& PC-PP1'; Table S1, sheet 'GO_enrichment'), whereas

439 genes involved in fruit ripening and seed dormancy were overexpressed (category 'up in PA-PP1

440 \& PC-PP1'; Table S1, sheet 'GO_enrichment'). These concomitant expression changes probably

441 reflect our histological observations that maternal-excess endosperms stopped dividing and

442 already started to differentiate at the early globular embryo stage (Roth et al. 2018a).

443 We thus suggest that hormone concentrations, regulating the progression through the cell

444 cycle, are mainly under maternal control and perturbed in opposite ways in (PA, PC) versus (AP,

$445 \mathrm{CP}$ ) endosperms, contributing to maternal- and paternal-excess endosperm morphologies and the

446 corresponding seed size differences. As proposed for interploid maize crosses by Leblanc et al.

447 (2002), parental dosage would influence the cell cycle such that (i) rapid mitotic arrest is due to

448 fast $\mathrm{G} / \mathrm{M}$ transitions in maternal-excess endosperm, and (ii) a longer phase of cell proliferation is

449 due to facilitated re-entry into the S-phase (DNA replication phase) and delayed G/M transitions

450 in paternal-excess endosperm.

451 Further, some authors have argued that HSF due to dosage imbalance is not a result of

452 perturbed imprinting per se but rather a sign that imprinted regulators of cytoplasmic growth rate

453 are misexpressed (von Wangenheim and Peterson 2004; Li and Dickinson 2010). All eukaryotic

454 cells progress through the cell cycle by means of precise control of cyclin concentrations.

455 Although cyclins and their regulation are only partially characterized in plants, it is known that

456 genes encoding cyclins are controlled by growth hormones (Inzé and De Veylder 2006, and

457 references therein). Parental control of hormones and other cell-cycle regulators would support

458 the hypothesis that imprinting evolved to ensure stable production of certain cell components

459 (Hurst and McVean 1998; Weisstein and Spencer 2003). Also, pervasive maternal control over

460 hormone supply could be interpreted as a coadapted control of cell signalling between the

461 endosperm and maternal tissues, thus allowing their synchronized development (Wolf and Hager

462 2006). 


\section{Parental excess in the endosperm mediates perturbed growth of maternal seed tissues}

465

466

467

468

469

470

471

472

473

474

475

476

477

478

479

480

481

482

483

484

485

486

487

488

489

490

491

492

493

We previously reported that sporophytic tissues were affected by the hybrid state, notably in CP crosses where both nucellus and seed coat were enlarged compared to [CC] developing seeds (Roth et al. 2018a). Based on studies of A. thaliana arf mutants, Schruff et al. (2006) proposed that impaired auxin regulation in sporophytic tissues altered seed size. As highlighted by our morphological data on some of the same wild tomato hybrid crosses studied here (Roth et al. 2018a), seed size and development was impaired in strong-HSF hybrids in a fashion similar to that observed by Schruff et al. (2006). However, in our study CP, CA and CC1 seeds inherited the same sporophytic genome (from mother $\mathrm{C} 1$ ) yet exhibited different seed viability levels, suggesting that the perturbation of auxin control is unlikely to originate in sporophytic tissues. Rather, auxin control is most likely first impaired in the endosperms of [AP] and [CP] hybrids and might subsequently mediate hormonal perturbation in sporophytic tissues.

Recent studies in A. thaliana have demonstrated that the endosperm-expressed AGL62 mediates the transport of auxin from the endosperm to the integuments and underlies nucellus degradation as well as integument initiation and growth during seed development (Figueiredo et al. 2016; Xu et al. 2016; Fiume et al. 2017). These results strengthen the hypothesis that AGL and auxin deregulation in the endosperm might be tightly linked and indicate that expression perturbation in the endosperm might trigger physiological abnormalities in maternal compartments of wild tomato abortive seeds. Our results thus emphasize the central role of the endosperm as a coordinator of seed development and growth, and they lend support to maternaloffspring coadaptation of gene expression in the seed (Berger et al. 2006; Wolf and Hager 2006; Nowack et al. 2010).

\section{Evolutionary implications of differences in effective ploidy for reproductive isolation}

We described the transcriptomes of hybrid endosperms obtained by reciprocally crossing three homoploid, closely related wild tomato lineages and found that transcriptomic differences were associated with phenotypic differences between intraspecific, partially viable, and completely inviable hybrid seeds. Our study system included two crosses with reciprocal strong-HSF phenotypes ([AP] and $[\mathrm{CP}]$ ) which also exhibited similar expression signatures. Thus, the $[\mathrm{AP}]$ and $[\mathrm{CP}]$ data reflect independently evolved yet similar biological features, suggesting shared 
494 molecular and physiological underpinnings of reproductive isolation between closely related 495 lineages.

496 Moreover, the asymmetric phenotypes and expression landscapes of strongly abortive 497 hybrid seeds indicate that parental conflict has facilitated the establishment of reproductive 498 isolation. More specifically, species $\mathrm{P}$ appears to drive HSF at both molecular and phenotypic 499 levels upon hybridization with lineages $\mathrm{C}$ or $\mathrm{A}$. We thus propose that $\mathrm{P}$ bears an increased 500 effective endosperm dosage, which can be interpreted as a higher effective ploidy (or EBN; 501 Johnston et al. 1980; Lafon-Placette and Köhler 2016). Recent empirical data in Capsella 502 suggest a positive correlation between levels of parental conflict within lineages and effective 503 ploidy (Rebernig et al. 2015; Lafon-Placette et al. 2018). As levels of parental conflict should 504 negatively correlate with relatedness between parents, such conflict is expected to decrease with 505 more intense inbreeding (Brandvain and Haig 2005). Although our study included only obligate outcrossers, lineages A, C and P harbor different levels of range-wide nucleotide diversity; specifically, $\mathrm{P}$ is the most diverse and A the least diverse lineage (Städler et al. 2008; Tellier et al. 2011; Labate et al. 2014). Range-wide nucleotide diversity should reflect long-term effective population size; all other things being equal, one would expect lower parental conflict between two randomly drawn plants from the least polymorphic (A) compared to the more polymorphic lineages ( $\mathrm{C}$ and, particularly, $\mathrm{P})$. In summary, we infer the relative effective ploidies between lineages to be $\mathrm{P}>>\mathrm{C} \geq \mathrm{A}$.

Lafon-Placette et al. (2018) identified higher numbers and expression levels of PEGs in the

514 obligatory outcrosser Capsella grandiflora (inferred to have the highest effective ploidy),

515 compared to the highly selfing species $C$. rubella and the more ancient selfer C. orientalis. In

516 contrast, our present and previously reported data (Roth et al. 2018b) entail that PEGs are

517 expressed at similar levels between A, C and P. We also found no significant differences in the 518 proportion of PEGs between A, C and P ( $\chi^{2}$ test, $\left.P>0.05\right)$. This lack of a clear signal regarding 519 the number and expression level of PEGs concomitant with apparent divergence in effective 520 ploidy within our study system can be reconciled due to the presumably closer levels of parental 521 conflict among our wild tomato lineages (with A, C and P all being obligate outcrossers), 522 compared to the Capsella system (Lafon-Placette et al. 2018).

523 Hybrid crosses between A and C produced variable proportions of viable seeds, suggesting 524 they have roughly comparable effective ploidies. Despite the occurrence of a few developmental 525 abnormalities, germinating [CA] F1 hybrids proved viable (Roth et al. 2018a), indicating that 
526 lineages $\mathrm{C}$ and $\mathrm{A}$ have accrued only few genetic incompatibilities. On the other hand, in the

527 crosses selected for the present study, AC seeds were larger than [AA] seeds and much larger

528 than CA seeds, suggesting a pattern of paternal excess for AC seeds (Roth et al. 2018a).

529 Consequently, C manifests signs of higher effective ploidy compared with A, but this dosage

530 difference appears small enough to be overcome by natural (endosperm) robustness to

531 hybridization, at least for a large fraction of seeds. Unfortunately, our dissection protocol does

532 not allow discriminating the endosperm from viable and non-viable seeds at the pre-globular

533 embryo stage, which could be useful to compare the transcriptomes of non-viable and viable

534 hybrids seeds from 'weak-HSF' crosses.

535 Importantly, we did not find significant genome-wide differences in expression levels

536 between $[\mathrm{AA}],[\mathrm{CC}]$ and $[\mathrm{PP}]$ endosperms and relatively few DEGs between them (Figures 1A,

537 3; Table 2; Table S1, sheet 'DEGs'). Hence, we propose that the property 'effective ploidy'

538 manifests as the stronger expression of a limited number of specific genes controlling dosage-

539 sensitive mechanisms, such as cell-cycle regulation; we provide a number of candidate

540 mechanisms controlling this feature. In particular, expression levels of AGL genes seem to

541 match the inferred genetic-value hierarchy; among the 41 putative AGL genes expressed in our

542 dataset, eight showed expression differences between the intraspecific crosses [AA], [CC] and

$543[\mathrm{PP}]$, such that $\mathrm{P}>\mathrm{C}, \mathrm{P}>\mathrm{A}$, and $\mathrm{C}>\mathrm{A}$. All eight genes were overexpressed in the paternal-

544 excess endosperms AP and CP, and four of them were also overexpressed in AC (the hybrid

545 combination exhibiting 'milder' paternal excess) such that AP $>$ PA, CP $>$ PC, and AC $>$ CA

546 (Table 3). These eight AGL genes are thus candidates for underpinning different effective

547 ploidies between tomato lineages, and as a consequence they might be decisive for the

548 occurrence and/or severity of HSF. Knocking out single or multiple AGL genes in parental

549 plants or modifying their expression levels in the endosperm, as has been done in Arabidopsis

550 (Walia et al. 2009; Kradolfer et al. 2013), would allow to validate their specific roles (if any) in

551 endosperm development and seed failure in Solanum. The expression patterns of AGL genes in

552 intraspecific and reciprocal hybrid comparisons indicate that they might be paternally expressed,

553 but imprinting could not be assessed for these genes.

554 While genomic imprinting — which is at the core of the parental conflict theory — probably

555 plays a crucial role in the evolution of effective ploidy (Lafon-Placette et al. 2018), our results

556 indicate that the causal functional drivers might not be restricted to imprinted genes. We suggest

557 that regulators of parent-specific expression, rather than strictly imprinted genes, might be 
558 responsible for evolutionary changes in effective ploidy. Specifically, frequent gene duplication

559 and neofunctionalization within specific genes families such as MADS-Box TFs (e.g. AGL

560 genes; Martínez-Castilla and Alvarez-Buylla 2003) and/or imprinted genes (Yoshida and

561 Kawabe 2013; Qiu et al. 2014), together with epigenetic variation impacting the control of

562 transposable elements (Pignatta et al. 2014; Lafon-Placette et al. 2018), might modify transcript

563 abundance and expression modes over very short evolutionary timescales. This could explain

564 why expression levels and imprinting status of specific genes vary between closely related

565 species such as wild tomato lineages (Roth et al. 2018b).

566 It has been shown that Arabidopsis AGL genes act within a network and that they can be

567 non-imprinted, maternally expressed, or paternally expressed (Walia et al. 2009; Bai and Settles

568 2015). Thus, any perturbation of expression levels among co-adapted AGLs in hybrids might be

569 at the root of the genome-wide perturbations observed in strong-HSF hybrids. Within species,

570 parental conflict might be stabilized by gene expression co-adaptation within functional

571 networks, which might also determine the property 'effective ploidy'. When parental species

572 have accrued diverged effective ploidies this equilibrium may be disrupted in their hybrids,

573 acting as a postzygotic reproductive barrier with varying quantitative effects depending on the

574 disparity of effective ploidies as manifested in the endosperm. In this context, our work is the

575 first to explore genome-wide expression correlates of dissimilar effective ploidies in the

576 endosperm, thus enabling the exploration of possible links between parental conflict, expression

577 dosage and HSF in flowering plants. It may also have practical applications in plant breeding, for

578 example to enhance hybridization success between crops and their wild relatives by

579 compensating effective ploidy differences with targeted, experimental ploidy changes. 


\section{Acknowledgments}

581 We are grateful to Maja Frei and Esther Zürcher for taking expert care of the plants, to Beatrice

582 Arnold for preparing RNA-Seq libraries, and to Claudia Michel, Silvia Kobel, and Joachim Hehl

583 for further technical help. We thank Margot Paris for her advice on experimental design and

584 analyses and Niklaus Zemp, Stefan Zoller and Mathias Scharmann for their generous

585 bioinformatics advice. We are grateful to Alex Widmer for his general support of this project.

586 We thank the C.M. Rick Tomato Genetics Resource Center at U.C. Davis for generously

587 supplying seed samples. We acknowledge the technical support on histological preparations and

588 laser-microdissections provided by SECTION-LAB (Hiroshima, Japan) and ScopeM (ETH

589 Zurich, Switzerland). Sequencing data were produced at the Functional Genomics Center Zurich

590 (University of Zurich, Switzerland). We thank the Genetic Diversity Center (ETH Zurich,

591 Switzerland) and the Swiss Institute for Bioinformatics (Lausanne, Switzerland) for providing

592 valuable tools and training for bioinformatics analyses. This work was supported by the Swiss

593 National Science Foundation [31003A_130702 to T.S.] and an ETH Research Grant [ETH-40

594 13-2 to T.S. and Alex Widmer].

\section{Literature Cited}

Alexa A, Rahnenführer J. 2016. topGO: enrichment analysis for gene ontology. $R$ Package Version 2.28.0.

Anders S, Pyl PT, Huber W. 2015. HTSeq-A Python framework to work with high-throughput sequencing data. Bioinformatics 31: 166-169.

Bai F, Settles AM. 2015. Imprinting in plants as a mechanism to generate seed phenotypic diversity. Frontiers in Plant Science 5: 780.

Baroux C, Spillane C, Grossniklaus U. 2002. Evolutionary origins of the endosperm in flowering plants. Genome Biology 3: reviews1026.1.

Beddows I, Reddy A, Kloesges T, Rose LE. 2017. Population genomics in wild tomatoes - the interplay of divergence and admixture. Genome Biology and Evolution 9: 3023-3038.

Berger F, Grini PE, Schnittger A. 2006. Endosperm: an integrator of seed growth and development. Current Opinion in Plant Biology 9: 664-670.

Brandvain Y, Haig D. 2005. Divergent mating systems and parental conflict as a barrier to 
hybridization in flowering plants. The American Naturalist 166: 330-338.

Burkart-Waco D, Ngo K, Dilkes B, Josefsson C, Comai L. 2013. Early disruption of maternalzygotic interaction and activation of defense-like responses in Arabidopsis interspecific crosses. The Plant Cell 25: 2037-2055.

Combes MC, Hueber Y, Dereeper A, Rialle S, Herrera JC, Lashermes P. 2015. Regulatory divergence between parental alleles determines gene expression patterns in hybrids. Genome Biology and Evolution 7: 1110-1121.

Cooper DC, Brink RA. 1945. Seed collapse following matings between diploid and tetraploid races of Lycopersicon pimpinellifolium. Genetics 30: 376-401.

Dilkes BP, Spielman M, Weizbauer R, Watson B, Burkart-Waco D, Scott RJ, Comai L. 2008. The maternally expressed WRKY transcription factor TTG2 controls lethality in interploidy crosses of Arabidopsis. PLoS Biology 6: 2707-2720.

Dion-Côté AM, Renaut S, Normandeau E, Bernatchez L. 2014. RNA-seq reveals transcriptomic shock involving transposable elements reactivation in hybrids of young lake whitefish species. Molecular Biology and Evolution 31: 1188-1199.

Figueiredo DD, Batista RA, Roszak PJ, Hennig L, Köhler C. 2016. Auxin production in the endosperm drives seed coat development in Arabidopsis. eLife 5: e20542.

Fiume E, Coen O, Xu WJ, Lepiniec L, Magnani E. 2017. Growth of the Arabidopsis subepidermal integument cell layers might require an endosperm signal. Plant Signaling and Behavior 12: e1339000.

Florez-Rueda AM. 2014. Postzygotic barriers to interbreeding in wild tomatoes: genomic imprinting and transcriptional signatures of hybrid seed failure. $\mathrm{PhD}$ thesis 22458 , ETH Zurich, Zurich, Switzerland.

Florez-Rueda AM, Paris M, Schmidt A, Widmer A, Grossniklaus U, Städler T. 2016. Genomic imprinting in the endosperm is systematically perturbed in abortive hybrid tomato seeds. Molecular Biology and Evolution 33: 2935-2946.

Gehring M, Bubb KL, Henikoff S. 2009. Extensive demethylation of repetitive elements during seed development underlies gene imprinting. Science 324: 1447-1451.

Gehring M, Missirian V, Henikoff S. 2011. Genomic analysis of parent-of-origin allelic expression in Arabidopsis thaliana seeds. PLoS ONE 6: e23687.

Haig D, Westoby M. 1991. Genomic imprinting in endosperm: its effect on seed development in crosses between species, and between different ploidies of the same species, and its 
implications for the evolution of apomixis. Philosophical Transactions of the Royal Society B: Biological Sciences 333: 1-13.

He G, Zhu X, Elling AA, Chen L, Wang X, Guo L, Liang M, He H, Zhang H, Chen F, et al. 2010. Global epigenetic and transcriptional trends among two rice subspecies and their reciprocal hybrids. The Plant Cell 22: 17-33.

Hegarty MJ, Barker GL, Brennan AC, Edwards KJ, Abbott RJ, Hiscock SJ. 2009. Extreme changes to gene expression associated with homoploid hybrid speciation. Molecular Ecology 18: 877-889.

Hurst LD, McVean GT. 1998. Do we understand the evolution of genomic imprinting? Current Opinion in Genetics and Development 8: 701-708.

Inzé D, De Veylder L. 2006. Cell cycle regulation in plant development. Annual Review of Genetics 40: 77-105.

Jeukens J, Renaut S, St-Cyr J, Nolte AW, Bernatchez L. 2010. The transcriptomics of sympatric dwarf and normal lake whitefish (Coregonus clupeaformis spp., Salmonidae) divergence as revealed by next-generation sequencing. Molecular Ecology 19: 5389-5403.

John P, Zhang K, Dong C, Diederich L, Wightman F. 1993. p34 ${ }^{\text {cdc2 }}$ related proteins in control of cell cycle progression, the switch between division and differentiation in tissue development, and stimulation of division by auxin and cytokinin. Australian Journal of Plant Physiology 20: 503-526.

Johnston SA, den Nijs TPM, Peloquin SJ, Hanneman RE. 1980. The significance of genic balance to endosperm development in interspecific crosses. Theoretical and Applied Genetics 57: 5-9.

Josefsson C, Dilkes B, Comai L. 2006. Parent-dependent loss of gene silencing during interspecies hybridization. Current Biology 16: 1322-1328.

Kang I-H, Steffen JG, Portereiko MF, Lloyd A, Drews GN. 2008. The AGL62 MADS domain protein regulates cellularization during endosperm development in Arabidopsis. The Plant Cell 20: 635-647.

Khaitovich P, Hellmann I, Enard W, Nowick K, Leinweber M, Franz H, Weiss G, Lachmann M, Pääbo S. 2005. Parallel patterns of evolution in the genomes and transcriptomes of humans and chimpanzees. Science 309: 1850-1854.

Kinsella, Rhoda J, Kähäri A, Haider S, Zamora J, Proctor G, Spudich G, Almeida-King J, Staines D, Derwent P, Kerhornou A, Kersey P. 2011. Ensembl BioMarts: a hub for data 
retrieval across taxonomic space. Database 2011: bar030.

Klosinska M, Picard CL, Gehring M. 2016. Conserved imprinting associated with unique epigenetic signatures in the Arabidopsis genus. Nature Plants 2: 16145.

Köhler C, Hennig L, Spillane C, Pien S, Gruissem W, Grossniklaus U. 2003. The Polycombgroup protein MEDEA regulates seed development by controlling expression of the MADS-box gene PHERES1. Genes and Development 17: 1540-1553.

Köhler C, Mittelsten Scheid O, Erilova A. 2010. The impact of the triploid block on the origin and evolution of polyploid plants. Trends in Genetics 26: 142-148.

Kradolfer D, Hennig L, Köhler C. 2013. Increased maternal genome dosage bypasses the requirement of the FIS Polycomb Repressive Complex 2 in Arabidopsis seed development. PLoS Genetics 9: e1003163.

Labate JA, Robertson LD, Strickler SR, Mueller LA. 2014. Genetic structure of the four wild tomato species in the Solanum peruvianum s.l. species complex. Genome 57: 169-180.

Lafon-Placette C, Köhler C. 2016. Endosperm-based postzygotic hybridization barriers: developmental mechanisms and evolutionary drivers. Molecular Ecology 25: 2620-2629. Lafon-Placette C, Johannessen IM, Hornslien KS, Ali MF, Bjerkan KN, Bramsiepe J, Glöckle BM, Rebernig CA, Brysting AK, Grini PE, et al. 2017. Endosperm-based hybridization barriers explain the pattern of gene flow between Arabidopsis lyrata and Arabidopsis arenosa in central Europe. Proceedings of the National Academy of Sciences U.S.A. 114: E1027-E1035.

Lafon-Placette C, Hatorangan MR, Steige KA, Cornille A, Lascoux M, Slotte T, Köhler C. 2018. Paternally expressed imprinted genes associate with hybridization barriers in Capsella. Nature Plants 4: 352-357.

Landry CR, Hartl DL, Ranz JM. 2007. Genome clashes in hybrids: insights from gene expression. Heredity 99: 483-493.

Leblanc O, Pointe C, Hernandez M. 2002. Cell cycle progression during endosperm development in Zea mays depends on parental dosage effects. The Plant Journal 32: 10571066.

Lester RN, Kang JH. 1998. Embryo and endosperm function and failure in Solanum species and hybrids. Annals of Botany 82: 445-453.

Li N, Dickinson HG. 2010. Balance between maternal and paternal alleles sets the timing of resource accumulation in the maize endosperm. Proceedings of the Royal Society B: 
Biological Sciences 277: 3-10.

Luo M, Taylor JM, Spriggs A, Zhang H, Wu X, Russell S, Singh M, Koltunow A. 2011. A genome-wide survey of imprinted genes in rice seeds reveals imprinting primarily occurs in the endosperm. PLoS Genetics 7: e1002125.

Martin M. 2011. Cutadapt removes adapter sequences from high-throughput sequencing reads. EMBnet J. 17: 10-12.

Martínez-Castilla LP, Alvarez-Buylla ER. 2003. Adaptive evolution in the Arabidopsis MADSbox gene family inferred from its complete resolved phylogeny. Proceedings of the National Academy of Sciences U.S.A. 100: 13407-13412.

Moyers BT, Rieseberg LH. 2013. Divergence in gene expression is uncoupled from divergence in coding sequence in a secondarily woody sunflower. International Journal of Plant Sciences 174: 1079-1089.

Nowack MK, Ungru A, Bjerkan KN, Grini PE, Schnittger A. 2010. Reproductive cross-talk: seed development in flowering plants. Biochemical Society Transactions 38: 604-612. Nuzhdin SV, Wayne ML, Harmon KL, McIntyre LM. 2004. Common pattern of evolution of gene expression level and protein sequence in Drosophila. Molecular Biology and Evolution 21: 1308-1317.

Okonechnikov K, Conesa A, García-Alcalde F. 2016. Qualimap 2: advanced multi-sample quality control for high-throughput sequencing data. Bioinformatics 32: 292-294.

Oneal E, Willis JH, Franks RG. 2016. Disruption of endosperm development is a major cause of hybrid seed inviability between Mimulus guttatus and Mimulus nudatus. New Phytologist 210: $1107-1120$.

Orozco-Arroyo G, Paolo D, Ezquer I, Colombo L. 2015. Networks controlling seed size in Arabidopsis. Plant Reproduction 28: 17-32.

Ortiz R, Ehlenfeldt MK. 1992. The importance of endosperm balance number in potato breeding and the evolution of tuber-bearing Solanum species. Euphytica 60: 105-113.

Patel RK, Jain M. 2012. NGS QC Toolkit: a toolkit for quality control of next generation sequencing data. PLoS ONE 7: e30619. doi: 10.1371/journal.pone.0030619.

Pignatta D, Erdmann RM, Scheer E, Picard CL, Bell GW, Gehring M. 2014. Natural epigenetic polymorphisms lead to intraspecific variation in Arabidopsis gene imprinting. eLife $\mathbf{3}$ : e03198.

Qiu Y, Liu S-L, Adams KL. 2014. Frequent changes in expression profile and accelerated 
sequence evolution of duplicated imprinted genes in Arabidopsis. Genome Biology and Evolution 6: 1830-1842.

R Development Core Team. 2014. R: a language and environment for statistical computing.

Vienna (Austria): R Foundation for Statistical Computing. URL: http://www.Rproject.org/.

Raza MA, Yu NN, Wang D, Cao LW, Gan SS, Chen LP. 2017. Differential DNA methylation and gene expression in reciprocal hybrids between Solanum lycopersicum and $S$. pimpinellifolium. DNA Research 24: 597-607.

Rebernig CA, Lafon-Placette C, Hatorangan MR, Slotte T, Köhler C. 2015. Non-reciprocal interspecies hybridization barriers in the Capsella genus are established in the endosperm. PLoS Genetics 11: e1005295.

Renaut S, Nolte AW, Bernatchez L. 2009. Gene expression divergence and hybrid misexpression between lake whitefish species pairs (Coregonus spp. Salmonidae). Molecular Biology and Evolution 26: 925-936.

Renaut S, Grassa CJ, Moyers BT, Kane NC, Rieseberg LH. 2012. The population genomics of sunflowers and genomic determinants of protein evolution revealed by RNAseq. Biology 1: $575-596$.

Robinson MD, McCarthy DJ, Smyth GK. 2010. edgeR: a Bioconductor package for differential expression analysis of digital gene expression data. Bioinformatics 26: 139-140.

Roth M, Florez-Rueda AM, Griesser S, Paris M, Städler T. 2018a. Incidence and developmental timing of endosperm failure in post-zygotic isolation between wild tomato lineages. Annals of Botany 121: 107-118.

Roth M, Florez-Rueda AM, Paris M, Städler T. 2018b. Wild tomato endosperm transcriptomes reveal common roles of genomic imprinting in both nuclear and cellular endosperm. The Plant Journal 95: 1084-1101.

Rushton PJ, Somssich IE, Ringler P, Shen QJ. 2010. WRKY transcription factors. Trends in Plant Science 15: 247-258.

Sabelli PA, Larkins BA. 2009. The contribution of cell cycle regulation to endosperm development. Sexual Plant Reproduction 22: 207-219.

Schruff MC, Spielman M, Tiwari S, Adams S, Fenby N, Scott RJ. 2006. The AUXIN RESPONSE FACTOR 2 gene of Arabidopsis links auxin signalling, cell division, and the size of seeds and other organs. Development 133: 251-261. 
Scott RJ, Spielman M, Bailey J, Dickinson HG. 1998. Parent-of-origin effects on seed development in Arabidopsis thaliana. Development 125: 3329-3341.

Sekine D, Ohnishi T, Furuumi H, Ono A, Yamada T, Kurata N, Kinoshita T. 2013. Dissection of two major components of the post-zygotic hybridization barrier in rice endosperm. The Plant Journal 76: 792-799.

Sharma DR, Kaur R, Kumar K. 1996. Embryo rescue in plants - a review. Euphytica 89: 325337.

Shirzadi R, Andersen ED, Bjerkan KN, Gloeckle BM, Heese M, Ungru A, Winge P, Koncz C, Aalen RB, Schnittger A, et al. 2011. Genome-wide transcript profiling of endosperm without paternal contribution identifies parent-of-origin-dependent regulation of AGAMOUS-LIKE36. PLoS Genetics 7: e1001303.

Städler T, Arunyawat U, Stephan W. 2008. Population genetics of speciation in two closely related wild tomatoes (Solanum section Lycopersicon). Genetics 178: 339-350.

Stelkens R, Seehausen O. 2009. Genetic distance between species predicts novel trait expression in their hybrids. Evolution 63: 884-897.

Stoute AI, Varenko V, King GJ, Scott RJ, Kurup S. 2012. Parental genome imbalance in Brassica oleracea causes asymmetric triploid block. The Plant Journal 71: 503-516.

Tellier A, Fischer I, Merino C, Xia H, Camus-Kulandaivelu L, Städler T, Stephan W. 2011. Fitness effects of derived deleterious mutations in four closely related wild tomato species with spatial structure. Heredity 107: 189-199.

The Tomato Genome Consortium. 2012. The tomato genome sequence provides insights into fleshy fruit evolution. Nature 485: 635-641.

Trapnell C, Pachter L, Salzberg SL. 2009. TopHat: discovering splice junctions with RNA-Seq. Bioinformatics 25: 1105-1111. doi: 10.1093/bioinformatics/btp120.

Valentine DH, Woodell SRJ. 1963. Studies in British primulas. X. Seed incompatibility in intraspecific and interspecific crosses at diploid and tetraploid levels. New Phytologist 62: $125-143$.

von Wangenheim KH, Peterson HP. 2004. Aberrant endosperm development in interploidy crosses reveals a timer of differentiation. Developmental Biology 270: 277-289.

Walia H, Josefsson C, Dilkes B, Kirkbride R, Harada J, Comai L. 2009. Dosage-dependent deregulation of an AGAMOUS-LIKE gene cluster contributes to interspecific incompatibility. Current Biology 19: 1128-1132. 
Wang L, Wang, S, Li W. 2012. RSeQC: quality control of RNA-seq experiments. Bioinformatics 28: $2184-2185$.

Warnes GR, Bolker B, Bonebakker L, Gentleman R, Liaw WHA, Lumley M, Maechler M, Magnusson A, Moeller A et al. 2016. gplots: various R programming tools for plotting data. $R$ Package Version 3.0.1.

Waters AJ, Makarevitch I, Eichten SR, Swanson-Wagner RA, Yeh C-T, Xu W, Schnable PS, Vaughn MW, Gehring M, Springer NM. 2011. Parent-of-origin effects on gene expression and DNA methylation in the maize endosperm. The Plant Cell 23: 4221-4233.

Waters AJ, Bilinski P, Eichten SR, Vaughn MW, Ross-Ibarra J, Gehring M, Springer NM. 2013. Comprehensive analysis of imprinted genes in maize reveals allelic variation for imprinting and limited conservation with other species. Proceedings of the National Academy of Sciences U.S.A. 110: 19639-19644.

Weisstein AE, Spencer HG. 2003. The evolution of genomic imprinting via variance minimization: an evolutionary genetic model. Genetics 165: 205-222.

Wilkinson L. 2011. Venneuler: Euler and Venn diagrams. R Package Version 1.1-0.

Wolf JB, Hager R. 2006. A maternal-offspring coadaptation theory for the evolution of genomic imprinting. PLoS Biology 4: e380.

Wolf JBW, Bayer T, Haubold B, Schilhabel M, Rosenstiel P, Tautz D. 2010. Nucleotide divergence vs. gene expression differentiation: comparative transcriptome sequencing in natural isolates from the carrion crow and its hybrid zone with the hooded crow. Molecular Ecology 19: 162-175.

Xu W, Fiume E, Coen O, Pechoux C, Lepiniec L, Magnani E. 2016. Endosperm and nucellus develop antagonistically in Arabidopsis seeds. The Plant Cell 28: 1343-1360.

Yoshida T, Kawabe A. 2013. Importance of gene duplication in the evolution of genomic imprinting revealed by molecular evolutionary analysis of the type I MADS-Box gene family in Arabidopsis species. PLoS ONE 8: e73588.

Zhang M, Li N, He W, Zhang H, Yang W, Liu B. 2016. Genome-wide screen of genes imprinted in sorghum endosperm, and the roles of allelic differential cytosine methylation. The Plant Journal 85: 424-436. 

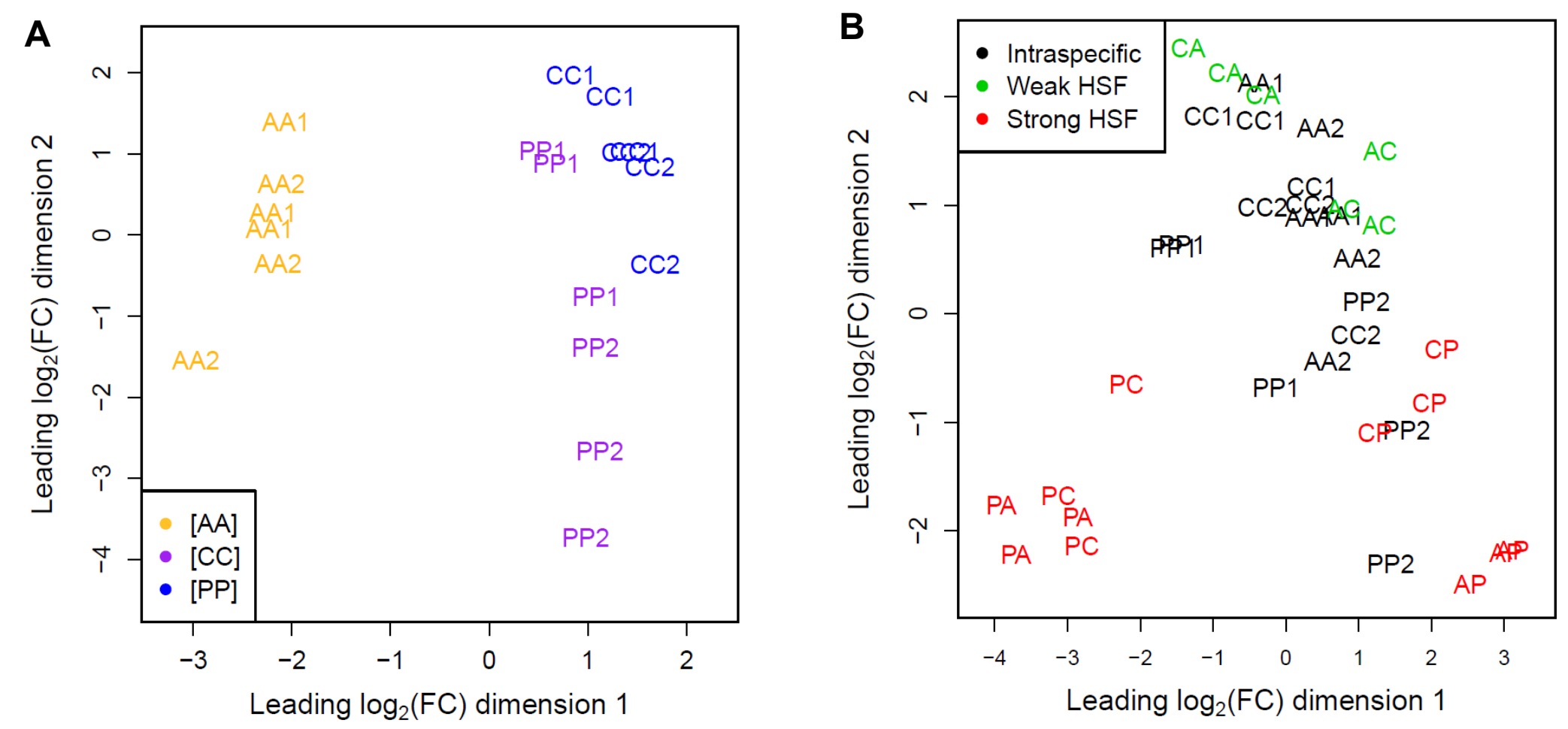

Figure 1 Multidimensional scaling plot representing the distances between endosperm samples (i.e. sequencing libraries) based on the joint expression levels of 22,006 genes. (A) All 18 samples representing intraspecific, reciprocal crosses [AA], [CC] and [PP]. (B) All 36 endosperm samples (i.e. intraspecific as well as hybrid) analyzed jointly. HSF, hybrid seed failure; $\log _{2}(\mathrm{FC}), \log _{2}$-fold change.

A, S. arcanum var. marañón; C, S. chilense; P, S. peruvianum. AA1, LA2185A $\times$ LA1626B; AA2, LA1626B $\times$ LA2185A; CC1, LA4329B $\times$ LA2748B; CC2, LA2748B $\times$ LA4329B; PP1, LA2744B $\times$ LA2964A; PP2, LA2964A $\times$ LA2744B; AC, LA2185A $\times$ LA4329B; CA, LA4329B $\times$ LA2185A; AP, LA2185A $\times$ LA2744B; PA, LA2744B $\times$ LA2185A; CP, LA4329B × LA2744B; PC, LA2744B $\times$ LA4329B. Cross specifications are identical in all other display items. 

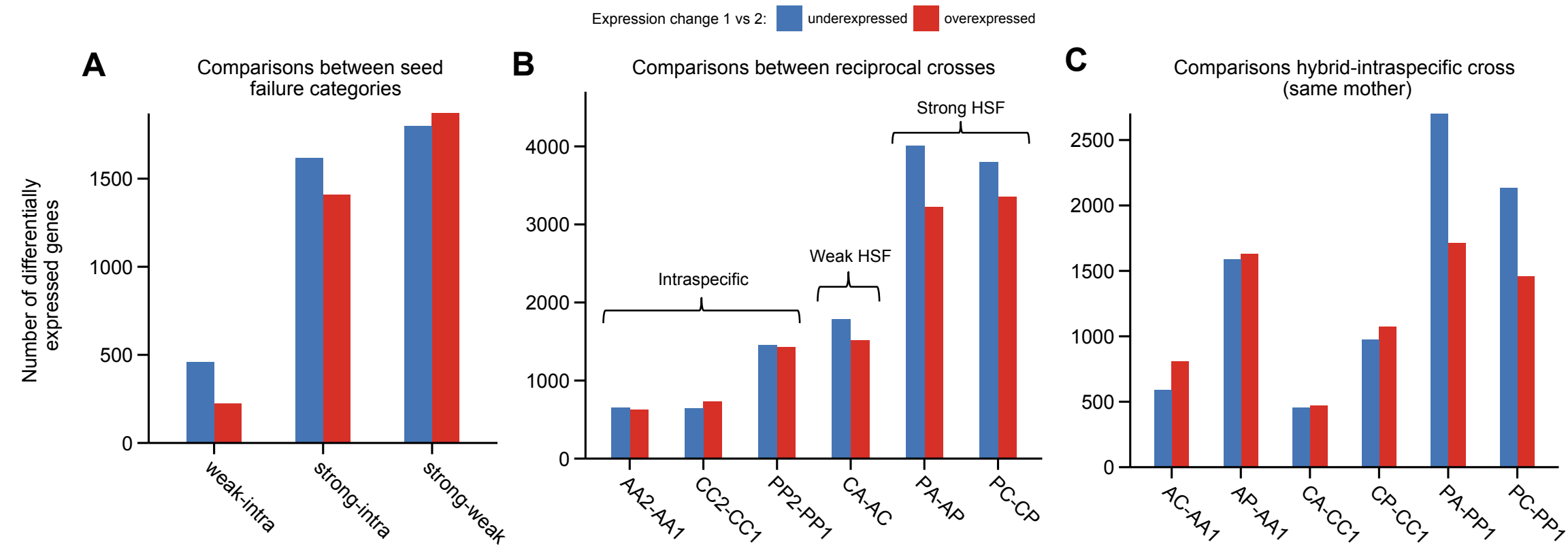

Figure 2 Overview of numbers of differentially expressed genes (DEGs) in different cross comparisons. The direction of expression change refers to the first term as compared to the second term (e.g. genes upregulated in 'weak-intra' refers to genes upregulated in 'weak' compared to 'intra'). Blue, underexpressed genes; red, overexpressed genes. (A) DEGs between designated classes of seed failure phenotype (i.e. intraspecific, weak hybrid seed failure (HSF), strong HSF). (B) DEGs between reciprocal crosses. (C) DEGs between hybrid and intraspecific crosses sharing the same mother. 

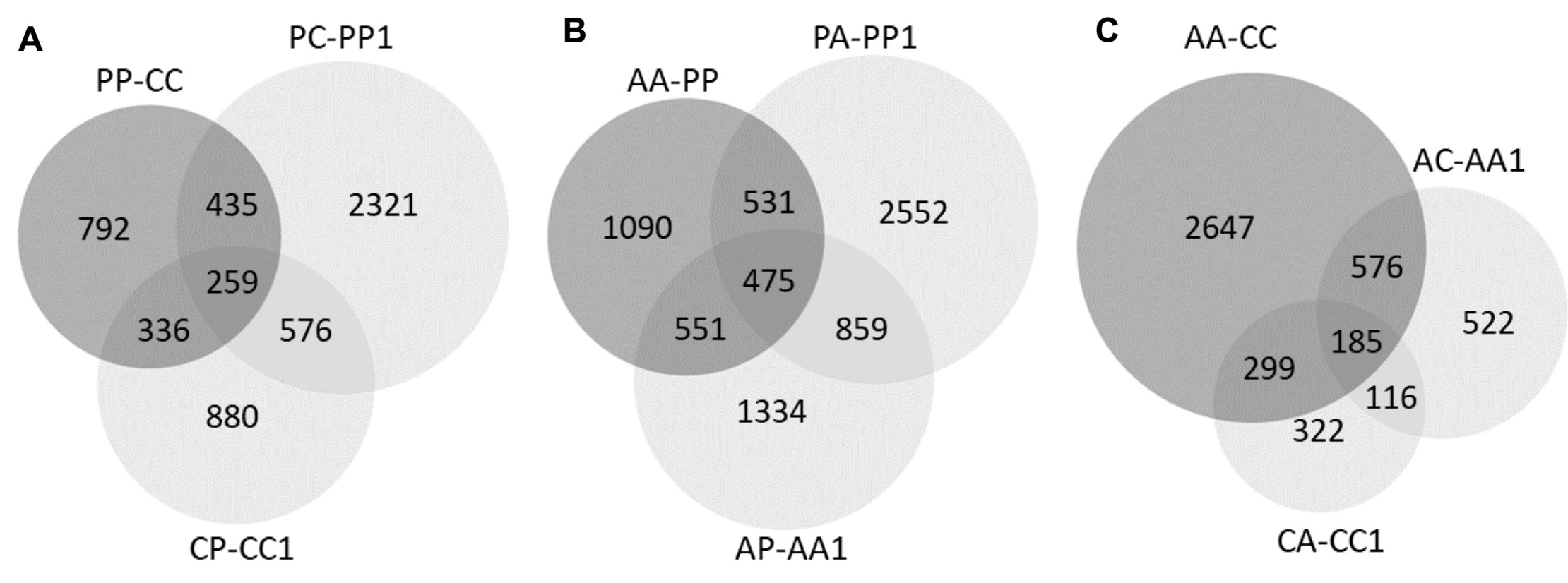

Figure 3 Venn diagrams representing the overlap between DEGs identified in different cross comparisons. (A) Comparisons involving lineages $\mathrm{C}$ and $\mathrm{P}$; (B) comparisons involving lineages $\mathrm{A}$ and $\mathrm{P}$; (C) comparisons involving lineages $\mathrm{A}$ and $\mathrm{C}$. 
A WRKY TFs $(n=44)$

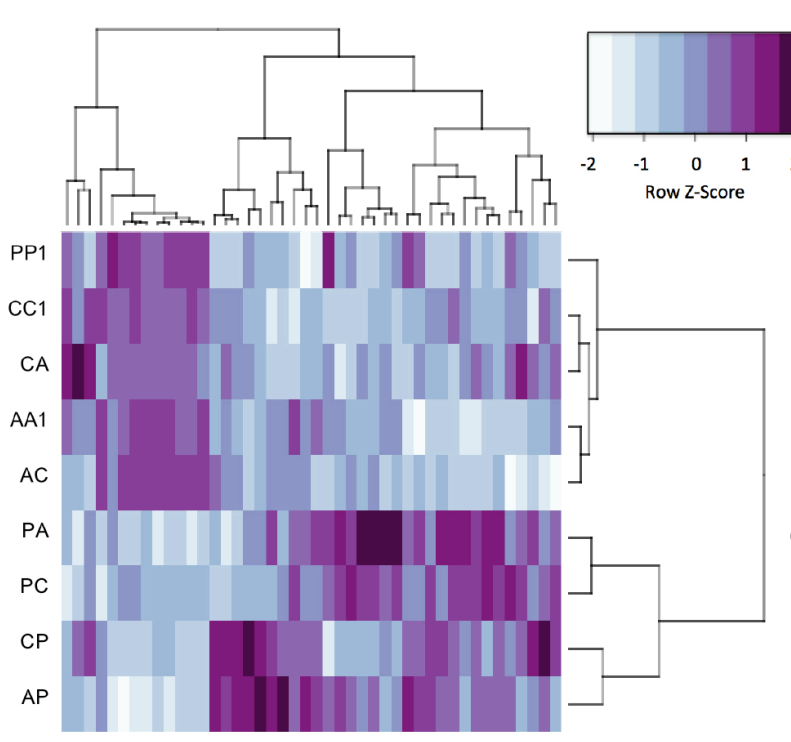

B MADS-Box TFs $(n=61)$

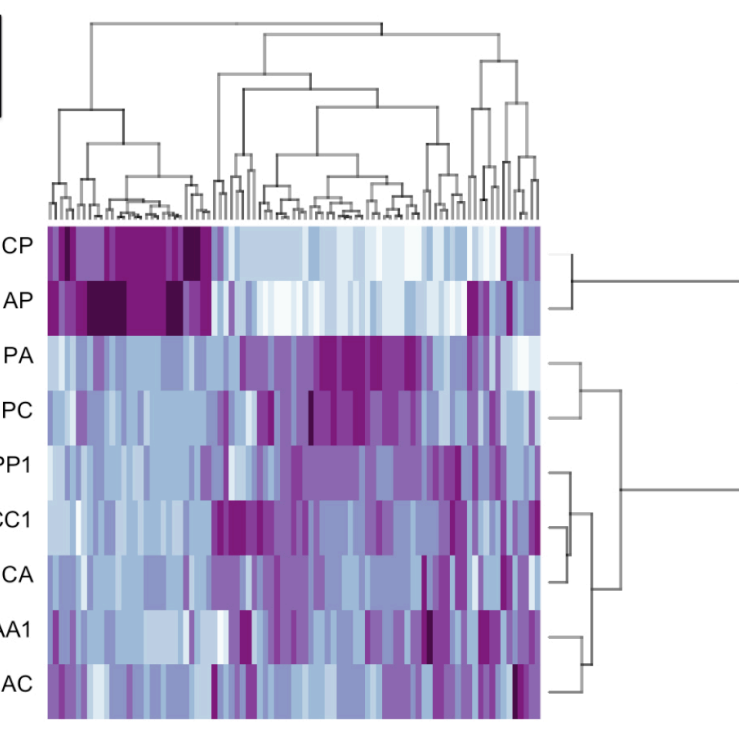

C E3 ubiquitin ligases $(n=20)$

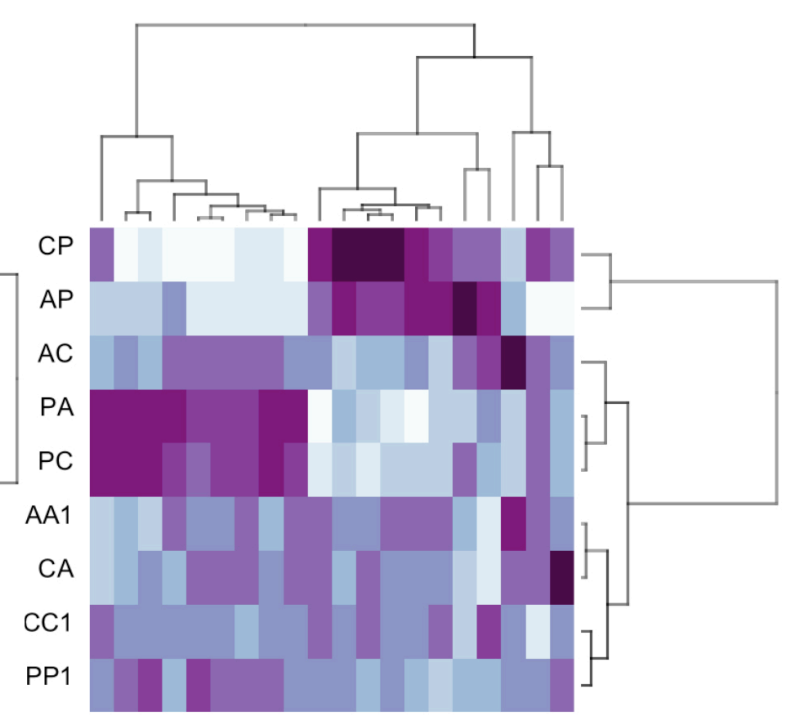

Figure 4 Heat maps representing expression variability for selected gene families among intraspecific and hybrid crosses sharing the same mother. (A) WRKY transcription factors (TFs); (B) MADS-Box TFs; (C) E3 ubiquitin ligases. Color scale according to Z-score (darker colors correspond to stronger expression values); samples and genes ordered by hierarchical clustering. 
Table 1 Top 10 GO-terms enriched among genes differentially expressed in reciprocal PA-AP and PC-CP hybrid endosperm

\begin{tabular}{|c|c|c|c|c|c|c|c|}
\hline Direction of change & $\begin{array}{l}\text { Ontology } \\
\text { category }\end{array}$ & $\begin{array}{l}\text { GO-term } \\
\text { ID }\end{array}$ & GO term description & $\begin{array}{l}\text { \#Annotated } \\
\text { genes }\end{array}$ & $\begin{array}{l}\text { \#Observed } \\
\text { genes }\end{array}$ & $\begin{array}{l}\text { \#Expected } \\
\text { genes }\end{array}$ & $\begin{array}{l}\text { Corrected } \\
P \text {-value }\end{array}$ \\
\hline \multirow{10}{*}{$\begin{array}{c}\text { Overexpressed } \\
\text { when } \mathrm{P} \text { is father } \\
\text { (AP and CP crosses) }\end{array}$} & MF & 4,161 & $\begin{array}{c}\text { dimethylallyltranstransferase } \\
\text { activity }\end{array}$ & 20 & 20 & 2 & $1.75 \mathrm{E}-17$ \\
\hline & MF & 3,677 & DNA binding & 1,358 & 247 & 163 & $3.25 \mathrm{E}-15$ \\
\hline & MF & 8,234 & cysteine-type peptidase activity & 133 & 49 & 16 & 2.00E-11 \\
\hline & MF & 46,983 & protein dimerization activity & 354 & 90 & 43 & 1.63E-09 \\
\hline & BP & 6,334 & nucleosome assembly & 41 & 20 & 5 & 7.75E-08 \\
\hline & BP & 6,508 & proteolysis & 684 & 122 & 78 & $7.75 \mathrm{E}-08$ \\
\hline & MF & 8,289 & lipid binding & 125 & 33 & 15 & $1.50 \mathrm{E}-07$ \\
\hline & MF & 1,104 & $\begin{array}{l}\text { RNA polymerase II transcription } \\
\text { cofactor activity }\end{array}$ & 28 & 13 & 3 & $5.58 \mathrm{E}-05$ \\
\hline & MF & 46,982 & protein heterodimerization activity & 118 & 31 & 14 & 1.14E-04 \\
\hline & MF & 30,599 & pectinesterase activity & 49 & 17 & 6 & 1.94E-04 \\
\hline \multirow{10}{*}{$\begin{array}{c}\text { Overexpressed } \\
\text { when } \mathrm{P} \text { is mother } \\
\text { (PA and PC crosses) }\end{array}$} & MF & 3,700 & transcription factor activity & 473 & 98 & 42 & 1.95E-14 \\
\hline & MF & 43,565 & sequence-specific DNA binding & 265 & 62 & 23 & $3.75 \mathrm{E}-11$ \\
\hline & MF & 8,146 & sulfotransferase activity & 18 & 11 & 2 & 7.17E-07 \\
\hline & $\mathrm{BP}$ & 6,355 & $\begin{array}{l}\text { regulation of transcription, } \\
\text { DNA-templated }\end{array}$ & 1,086 & 143 & 98 & 2.05E-06 \\
\hline & MF & 45,735 & nutrient reservoir activity & 30 & 13 & 3 & $6.63 \mathrm{E}-06$ \\
\hline & $\mathrm{BP}$ & 9,734 & auxin-activated signaling pathway & 48 & 17 & 4 & $4.75 \mathrm{E}-05$ \\
\hline & MF & 4,722 & $\begin{array}{l}\text { protein serine/threonine } \\
\text { phosphatase activity }\end{array}$ & 79 & 20 & 7 & $1.20 \mathrm{E}-04$ \\
\hline & MF & 8,289 & lipid binding & 125 & 25 & 11 & 2.08E-04 \\
\hline & MF & 4,674 & $\begin{array}{l}\text { protein serine/threonine kinase } \\
\text { activity }\end{array}$ & 413 & 61 & 36 & 4.36E-04 \\
\hline & BP & 6,468 & protein phosphorylation & 934 & 122 & 84 & 7.67E-04 \\
\hline
\end{tabular}

MF, molecular function; BP, biological process. 
Table 3 Expression pattern and annotation of eight AGL genes potentially contributing to differences in effective ploidy between species

\begin{tabular}{|c|c|c|c|c|c|c|c|c|}
\hline \multirow[b]{2}{*}{ Gene model } & \multicolumn{3}{|c|}{ Among-species comparisons } & \multicolumn{3}{|c|}{ Reciprocal hybrid comparisons } & \multicolumn{2}{|r|}{ Source } \\
\hline & {$[\mathrm{PP}]-[\mathrm{AA}]$} & {$[P P]-[C C]$} & {$[\mathrm{CC}]-[\mathrm{AA}]$} & AP-PA & CP-PC & AC-CA & TFDB v $3.0^{a}$ & Annotation in ITAG2.4 \\
\hline Solyc01g097850 & UP & UP & UP & UP & UP & UP & AGAMOUS-like 62 & MADS-box TF 31 \\
\hline Solyc01g103870 & UP & UP & UP & UP & UP & ns & AGAMOUS-like 98 & SRF-type TF family protein \\
\hline Solyc03g033570 & UP & UP & UP & UP & UP & UP & Not found & $\begin{array}{l}\text { Agamous-like MADS-box protein } \\
\text { AGL62 }\end{array}$ \\
\hline Solyc04g025110 & UP & UP & UP & UP & UP & ns & AGAMOUS-like 62 & MADS-box TF 8 \\
\hline Solyc04g047870 & UP & UP & UP & UP & UP & ns & AGAMOUS-like 62 & MADS box TF 1 \\
\hline Solyc06g054680 & UP & UP & UP & UP & UP & UP & AGAMOUS-like 62 & MADS-box TF \\
\hline Solyc11g069770 & UP & UP & UP & UP & UP & UP & AGAMOUS-like 62 & TF MADS-box \\
\hline Solyc12g016150 & UP & UP & UP & UP & UP & ns & AGAMOUS-like 96 & MADS-box protein (fragment) \\
\hline
\end{tabular}

TF, transcription factor. Up, overexpressed in first cross of each pairwise comparison; ns, non-significant expression change.

${ }^{a}$ Transcription Factor Database v3.0 (http://planttfdb_v3.cbi.pku.edu.cn/). 
bioRxiv preprint doi: https://doi.org/10.1101/459925; this version posted November 2, 2018. The copyright holder for this preprint (which

was not certified by peer review) is the author/funder, who has granted bioRxiv a license to display the preprint in perpetuity. It is made available under aCC-BY-NC-ND 4.0 International license.

Table 2 Contingency table of differentially expressed genes (DEGs) in among-species vs. reciprocal hybrid comparisons

\begin{tabular}{|c|c|c|c|}
\hline & $\begin{array}{c}\text { Up in PA } \\
\text { (down in AP) }\end{array}$ & $\begin{array}{l}\text { Down in PA } \\
\text { (up in AP) }\end{array}$ & Total \# DEGs found \\
\hline $\begin{array}{c}\text { Up in }[P P] \\
\text { (down in }[A A])\end{array}$ & 544 & 385 & 1,471 \\
\hline $\begin{array}{c}\text { Down in }[P P] \\
\text { (up in }[A A] \text { ) }\end{array}$ & 98 & 588 & 1,176 \\
\hline \multirow[t]{2}{*}{ Total \# DEGs found } & 3,222 & 4,005 & \\
\hline & $\begin{array}{c}\text { Up in PC } \\
\text { (down in CP) }\end{array}$ & $\begin{array}{l}\text { Down in } \mathrm{PC} \\
\text { (up in } \mathrm{CP} \text { ) }\end{array}$ & Total \# DEGs found \\
\hline $\begin{array}{c}\text { Up in }[\mathrm{PP}] \\
\text { (down in [CC]) }\end{array}$ & 409 & 270 & 971 \\
\hline $\begin{array}{l}\text { Down in [PP] } \\
\text { (up in [CC]) }\end{array}$ & 79 & 407 & 851 \\
\hline \multirow[t]{2}{*}{ Total \# DEGs found } & 3,354 & 3,799 & \\
\hline & $\begin{array}{c}\text { Up in } C A \\
\text { (down in } A C \text { ) }\end{array}$ & $\begin{array}{l}\text { Down in } C A \\
\text { (up in } A C \text { ) }\end{array}$ & Total \# DEGs found \\
\hline $\begin{array}{c}\text { Up in }[\mathrm{CC}] \\
\text { (down in }[\mathrm{AA}] \text { ) }\end{array}$ & 392 & 258 & 2,198 \\
\hline $\begin{array}{c}\text { Down in }[C C] \\
\text { (up in }[A A] \text { ) }\end{array}$ & 236 & 351 & 1,509 \\
\hline Total \# DEGs found & 1,513 & 1,784 & \\
\hline
\end{tabular}

Comparisons among species (first column) each include both reciprocal crosses (e.g. PP1, PP2, $A A 1$ and $A A 2$ were used to compare expression levels of species $P$ and $A$ ). 


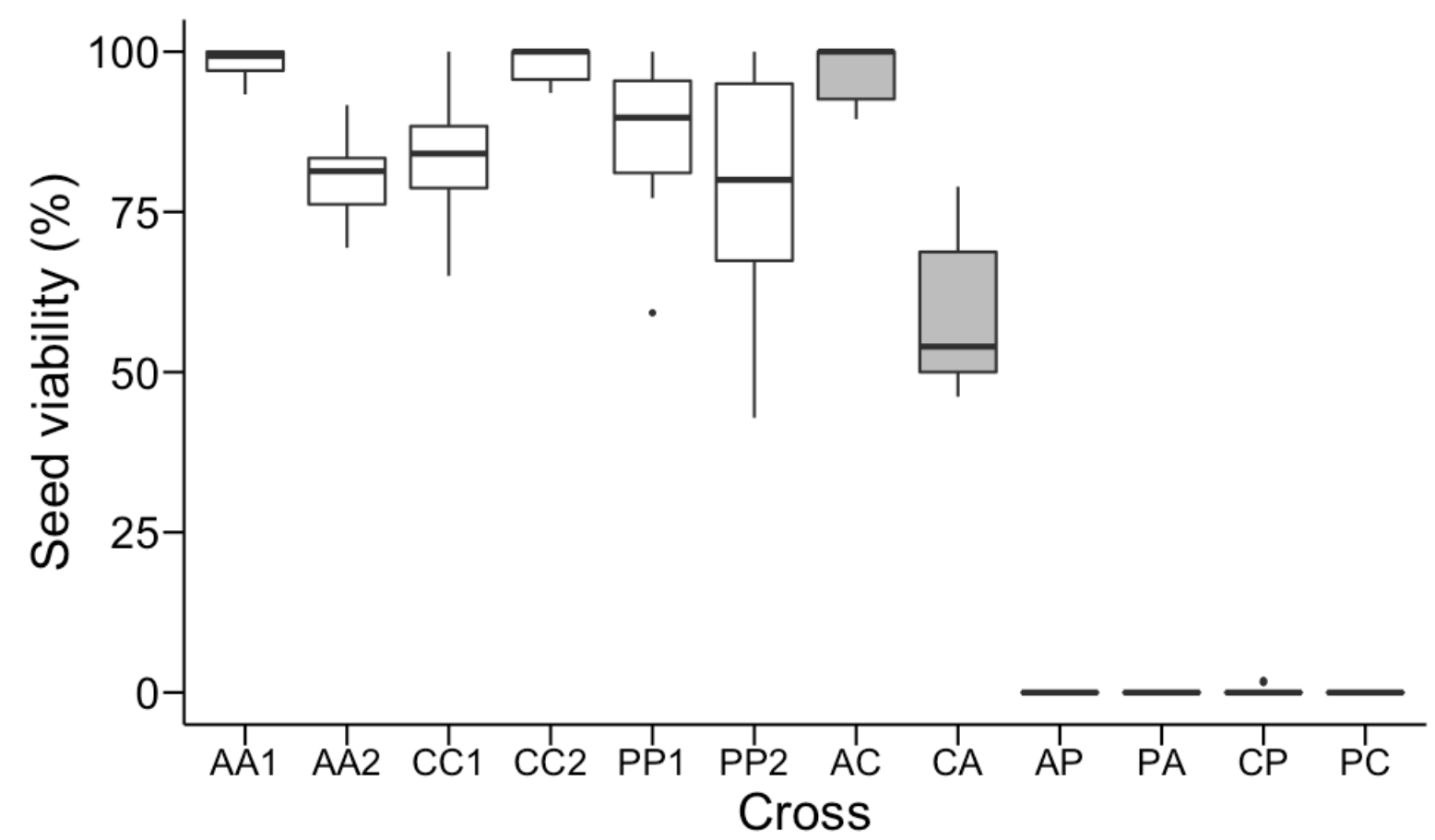

Figure S1 Box plot representing the distribution of seed viability in all crosses used in this study. Assessment of seed viability was performed visually at fruit maturity 60 days after pollination (data source: Roth et al. 2018a). Open boxes, intraspecific crosses; grey boxes, hybrid crosses. A, S. arcanum var. marañón; C, S. chilense; P, S. peruvianum. AA1, LA2185A × LA1626B; AA2, LA1626B × LA2185A; CC1, LA4329B × LA2748B; CC2, LA2748B × LA4329B; PP1, LA2744B × LA2964A; PP2, LA2964A × LA2744B; AC, LA2185A × LA4329B; CA, LA4329B $\times$ LA2185A; AP, LA2185A $\times$ LA2744B; PA, LA2744B $\times$ LA2185A; CP, LA4329B $\times$ LA2744B; PC, LA2744B $\times$ LA4329B. Cross specifications are identical in all other display items. 


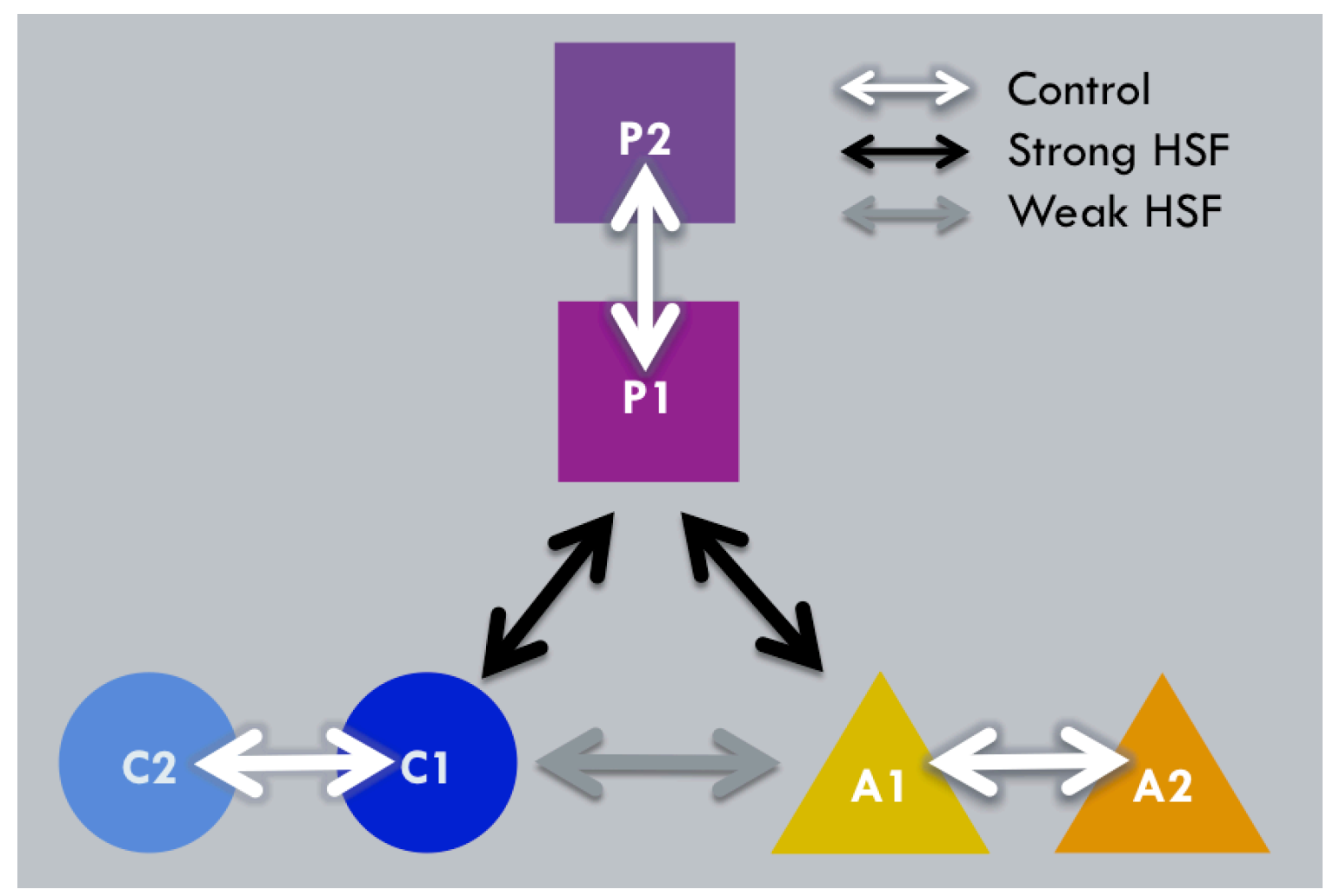

Figure S2 Crossing design representing the six reciprocal crosses used for our endosperm RNASeq experiment. Arrows represent reciprocal crosses (white, intraspecific; black, hybrid crosses resulting in strong hybrid seed failure (HSF); grey, hybrid crosses resulting in weak HSF). Each shape represents one wild tomato genotype sampled from separate populations in species A $(S$. arcanum var. marañón; triangles), C (S. chilense; circles) and P (S. peruvianum; squares). A1, LA2185A; A2, LA1626B; C1, LA4329B; C2, LA2748B; P1, LA2744B; P2, LA2964A.

Table S1 File composed of four data sheets: 'Contrasts' contains the list of 18 comparisons with their corresponding contrasts used in this study; 'DEGs' summarizes differential gene expression (DGE) for each of them; 'GO_enrichment' summarizes GO-term enrichments for differentially expressed genes (DEGs) in selected categories; 'DGE_imprinted_genes' lists the status of candidate imprinted genes and their differential expression in all tested contrasts (separate Excel data file). 